\title{
Effect of Spironolactone on Doxorubicin Induced Cardiomyopathy in Adult Male Albino Rat: Histological, Pharmacological and Biochemical Study
}

\author{
MARWA O. ABDL EL ALL, M.D. ${ }^{\mathbf{1}}$; HASSAN S. EL SAYED ALI, M.D. ${ }^{2}$; HEBA H. ROHYM, M.D. ${ }^{\mathbf{3}}$; \\ AYMAN M. HELAL, M.D. ; RADWA M. AHMED, M.D. ' and \\ MOHAMED M. KHAMISS ABD EL GUAAD, M.D. \\ The Departments of Histology , Medical Biochemistry , Forensic Medicine \& Clinical Toxicology ${ }^{3}$, Pharmacology, \\ Anatomy \& Embryology and Physiology, Faculty of Medicine, Fayoum University
}

\begin{abstract}
Background: Doxorubicin, an anthracycline drug, is an effective chemotherapeutic agent for treatment of solid tumors and hematological malignancies. However, its clinical use is limited by cardiotoxicity, such as irreversible degenerative cardiomyopathy, electrocardiographic changes, and congestive heart failure. The studies have been proved that spironolactone can ameleorate cardiac fibrosis. This drug is already indicated in treatment of doxorubicin-induced cardiotoxicity to prevent further deterioration.
\end{abstract}

Aim of Study: Is to elucidate protective and therapeutic effect of spironolactone on doxorubicin induced cardiomyopathy.

Material and Methods: Fifty adult male albino rats weighing 180-220g were used in this study. The rats were divided into five groups 10 rats each: Group I (Normal control): Rats received single injection of saline solution $0.9 \%$ intraperitoneally once daily for 14 days. Group II (Doxorubicin adminstraion group): Rats were injected once with doxorubicin intaperitoneally at a dose of $10 \mathrm{mg} / \mathrm{kg}$ once daily for 14 days. Group III (Doxorubicin and spironolactone pre-administration group): Rats were injected once with doxorubicin intaperitoneally at a dose of $10 \mathrm{mg} / \mathrm{kg}$ once daily for 14 days and pretreated with spironolactone for seven days before doxorubicin administration Group IV (Doxorubicin and spironolactone co-administration group): Rats were injected once with doxorubicin intaperitoneally at a dose of $10 \mathrm{mg} / \mathrm{kg}$ once daily and co-treated with spironolactone for 14 days Group V (Doxorubicin and spironolactone Post-administration group): Rats were injected once with doxorubicin intaperitoneally at a dose of $10 \mathrm{mg} / \mathrm{kg}$ once daily for 14 days and followed by spironolactone for 7 days. The dose of spironolactone was $40 \mathrm{mg} / \mathrm{kg}$ given by oral gavage.

Results: Doxorubicin injection exerted various histological and laboratory alterations such as myocardial fibrosis, ballooned mitochondria and elevated cardiac enzymes. Spironol-

Correspondence to: Dr. Marwa O. Abdl El All, The Department of Histology, Faculty of Medicine, Fayoum University actone could improve all histological and functional deterioration exerted by doxorubicin injection especially when given before doxorubicin administration.

Conclusion: It could be concluded that Spironolactone could prevent the adverse histological and functional alterations induced by intraperitoneal injection of doxorubicin in the myocardium of adult male albino rat.

Key Words: Doxorubicin - Spironolactone - Rat-Myocardium.

\section{Introduction}

CANCER is the second leading cause of death after cardiovascular diseases over the world. In recent years, the survival rate of patients suffering from oncological diseases has markedly increased due to developments in modern oncotherapy. However, the cardiovascular side effects of radiotherapy and chemotherapy have limited the success of oncotherapeutic regimens. Despite intensive ongoing research efforts, chemotherapy-induced cardiotoxicity remains an unresolved clinical problem, that may exert cardiomyopathy with consequent heart failure. Nowadays, the use of classic cytotoxic agents such as anthracyclines has been re-evaluated due to the evolving role of targeted and immunooncology drugs, however, they still have a cardinal role in the treatment of different tumours [1].

Doxorubicin, an anthracycline drug, is an effective chemotherapeutic agent for treatment of solid tumors and hematological malignancies. However, its clinical use is limited by cardiotoxicity, such as irreversible degenerative cardiomyopathy, electrocardiographic changes, and congestive heart failure [2]. 
Spironolactone an aldosterone antagonist the studies have been proved that spironolactone can ameleorate cardiac fibrosis. This drug is already indicated in treatment of doxorubicin-induced cardiotoxicity to prevent further deterioration and to protect both myocardial systolic and diastolic functions in the patients $[3,4]$.

\section{Subjects and Methods}

\section{Chemicals: [2]:}

1- Doxorubicin: Doxorubicin (Adriamycin): Rats were injected intraperitoneally with doxorubicin in normal saline at a dose of $10 \mathrm{mg} / \mathrm{kg}$. Adriamycin was purchased from Phrmcia, Egypt.

2- Spironolactone (Aldactone): The dose of spironolactone was $40 \mathrm{mg} / \mathrm{kg}$ that was dissolved in normal saline given by oral gavage. Aldactone (100mg tablets) was purchased from Pfizer, US.

\section{Animals:}

Fifty adult male albino rats weighing $180-220 \mathrm{~g}$ were used in this study. They were obtained from the animal house, Faculty of Medicine, Cairo University. During 2019 the rats were housed in separate cages and maintained under standard laboratory and environmental conditions with standard rat chow. The rats were divided into five groups 10 rats each:

Group I (Normal control): Rats received single injection of saline solution $0.9 \%$ intraperitoneally once daily for 14 days.

Group II (Doxorubicin adminstraion group): Rats were injected once with doxorubicin intaperitoneally at a dose of $10 \mathrm{mg} / \mathrm{kg}$ once daily for 14 days.

Group III (Doxorubicin and spironolactone preadministration group): Rats were injected once with doxorubicin intaperitoneally at a dose of $10 \mathrm{mg} / \mathrm{kg}$ once daily for 14 days and pretreated with spironolactone orally at a dose of $40 \mathrm{mg} / \mathrm{kg}$ once daily for seven days before doxorubicin administration.

Group IV (Doxorubicin and spironolactone co- administration group): Rats were injected once with doxorubicin intaperitoneally at a dose of $10 \mathrm{mg} / \mathrm{kg}$ once daily and co-treated with spironolactone orally at a dose of $40 \mathrm{mg} / \mathrm{kg}$ once daily for 14 days.

Group V (Doxorubicin and spironolactone Post-administration group): Rats were injected once with doxorubicin intaperitoneally at a dose of $10 \mathrm{mg} / \mathrm{kg}$ once daily for 14 days and followed by spironolactone orally at a dose of $40 \mathrm{mg} / \mathrm{kg}$ once daily for 7 days.
Methods: The heart was excised and processed for the following studies:

1- Light microscopic study using hematoxylin and eosin and Masson trichrome stains: Methods of light microscopy [5]:

\section{A- Haematoxylin and eosin stain:}

The cardiac tissues were fixed in $4 \%$ paraformaldehyde. The histological sections were deparaffinized in xylene, rehydrated through a graded series of ethanol, and washed in running water. The sections were then immersed in Harris' hematoxylin for two minutes, washed in running water (five minutes), rinsed in distilled water (one minute), stained in an aqueous solution of eosin (five minutes), and dehydrated in ascending concentrations of ethanol. Next, the sections were cleared in xylene (three successive changes, one minute each) and mounted under a cover-slip.

\section{B-Masson's trichrome staining:}

The histological sections were deparaffinized, rehydrated, washed in running water (two minutes), immersed in 5\% iron alum (ten minutes) and Regaud's hematoxylin (three minutes), and rinsed in distilled water, 95\% alcohol, and picric alcohol. Then, the sections were washed again in running water (ten minutes), rapidly immersed in xylidine ponceau aqueous solution (three minutes), distilled water and $1 \%$ glacial acetic acid, and $1 \%$ phosphomolybdic acid (three minutes). Next, they were rinsed again in distilled water, immersed in aniline blue for 2-5 minutes, dehydrated, cleared, and mounted under a cover-slip.

\section{Electron microscopic examination: [6]:}

Small cylinders ( $4 \mathrm{~mm}$ long $\mathrm{x} \times 1 \mathrm{~mm} \times 1 \mathrm{~mm}$ ) of tissue were prepared from each heart section. These cardiac tissue samples were fixed by immersion in vials which contained $1 \mathrm{~mL}$ of mixed solution glutaraldehyde $1.25 \%$ and paraformaldehyde $1 \%$ in a phosphate-buffered saline (PBS) buffer solution, at $4^{\circ} \mathrm{C}$ for $48 \mathrm{~h}$. Samples were washed with PBS 0.14M $(\mathrm{pH}=7.4)$ for $45 \mathrm{~min}$. This process was repeated three times. Subsequent steps were carried out by the Serveis Cientifico-Tècnics (SCT) of the Universitat de Barcelona. In the SCT, samples were subjected to a post-fixation process in osmium tetraoxide (OsO4) 1\% in PBS for 1h. Samples were then dehydrated in acetone. They were left in different solutions with ascending acetone concentrations for $10 \mathrm{~min}$. Dehydrated samples were mounted in Spurr's epoxide resin blocks. The resin blocks were cut and semithin sections $(1.5 \mu \mathrm{m})$ were processed. These sections were then observed with an optic microscope at 40x to choose the regions of interest for processing and analysing 
using TEM. The chosen regions were cut and put into square and eyelet grids. They were contrasted so that they could be studied with TEM.

2- mRNA analysis: Real time polymerase chain reaction analysis of:

a- Tumour necrotic factor alpha (TNF alpha). $b$ Interleukin 1-beta. $(I L-1 b)$ : [7,8]:

Real-Time Quantitative PCR Analysis: The mRNA concentrations of TNF- $\alpha$, IL $1-b$ and $\beta$ actin in the rat heart specimens were quantified by quantitative real-time PCR. $\beta$-actin was used as a housekeeping gene to normalize the gene expression data. The primer information for all the genes is:

- Sequences for real-time PCR primers.

- $\beta$-Actin: ACCGCAAATGCTTCTAAACC ATAAAGCCATGCCAATCTCG

- TNF- $\alpha$ : TGTGTATGTGCAGCAACCCGTAGTCATTGCAATTTGGACAGAAGT

- IL-1 $\beta$ : TCTTCTACCGCCTGGACACG TAGGTGGCGATGTTGACCTG

Total RNA was obtained using TRIzol reagent (Invitrogen, Carlsbad, CA, USA) according to the manufacturer's protocol, and the RNA integrity was assessed via $1 \%$ agarose gel electrophoresis. The RNA concentrations and purity were determined from OD260/280 readings (ratio > 1.8) using a NanoDrop ND-1000 spectrophotometer (NanoDrop Technologies, Wilmington, DE) and adjusted to the same concentration. The RNA was reverse transcribed to cDNA by using a PrimeScript RT reagent kit (Takara, Shiga, Japan). Real-time quantitative PCR was carried out in a 7500 Real-Time PCR system (Applied Biosystems, Foster City, CA, USA) using a SYBR Green PCR kit (Roche Diagnostics, Laval, Quebec, Canada). All samples were analyzed in triplicate, and the results were expressed as $2-\Delta \Delta \mathrm{CT}$. Each cycle consisted of denaturation at $95^{\circ} \mathrm{C}$ for $10 \mathrm{~s}$, annealing at $95^{\circ} \mathrm{C}$ for $5 \mathrm{~s}$, and extension at $60^{\circ} \mathrm{C}$ for $34 \mathrm{~s}$. Each sample was measured in triplicate, and the average values were obtained.

c- Endothelial nitric oxide (e NO): [9]: Total RNA was extracted from $10 \mathrm{mg}$ of rat heart tissue with the RNX-Plus solution kit (Cinagen Co., Tehran, Iran). cDNA synthesis was performed using Thermo Scientific RevertAid Reverse Transcriptase in accordance with the manufacturers' instructions. Primers were designed using primer 3 and Gene Runner. Amplifications were performed in a Rotor Gene 6000 real-time PCR machine (Corbett, Life science, Sydney, Australia). Target genes were normalized with $B$-actin as reference. Fold changes in mRNA expression for: eNOS, genes were calculated by the $2 \Delta \Delta \mathrm{Ct}$ method. Primer sequences employed are: eNO Forward: TGACCCTCACCGATACAACA, Reverse: CGGGTGTCTAGATCCATGC.; $\beta$-actin: Forward: GCGTCCACCCGCGAGTACAAC Reverse: CGACGACGAG CGCAGCGATA.

\section{3- Biochemical analysis:}

a- Antioxidant enzymes: Cardiac superoxide dismutase (SOD) glutathione peroxidise (GSH) enzymes and Lipid perodixation marker: Malondialdehyde (MDA) production.

$b$ - Cardiac enzymes: Serum levels of: Troponin1. Creatin kinase (CK) and CK-MB.

4- Statistical analysis of data:

Biochemical analysis: [10]:

Tissue malondialdehyde measurements:

Malondialdehyde measurements were based on the method used by Ohkawa et al. [14], involving spectrophotometric measurement of absorbance of the pink-stained complex formed by thiobarbituric acid (TBA) and MDA. The tissue homogenate sample $(0.1 \mathrm{~mL})$ was added to a solution containing $0.2 \mathrm{ml}$ of $80 \mathrm{~g} / \mathrm{L}$ sodium dodecyl sulfate, $1.5 \mathrm{~mL}$ of $200 \mathrm{~g} / \mathrm{L}$ acetic acid, $1.5 \mathrm{~mL}$ of $8 \mathrm{~g} / \mathrm{L} 2$-thiobarbiturate, and $0.3 \mathrm{~mL}$ distilled water. The mixture was incubated at $95^{\circ} \mathrm{C}$ for $1 \mathrm{~h}$. Upon cooling, $5 \mathrm{~mL}$ of $\mathrm{n}$ butanol: Pyridine $(15: 1)$ was added. The mixture was vortexed for $1 \mathrm{~min}$ and centrifuged for $30 \mathrm{~min}$ at $4000 \mathrm{rpm}$. The absorbance of the supernatant was measured at $532 \mathrm{~nm}$. The standard curve was obtained using 1,1,3,3-tetramethoxypropane [14].

\section{Total glutathione measurements:}

DTNB [5,5'-dithiobis (2-nitrobenzoic acid)] disulfite is chromogenic in the medium, and DTNB is reduced easily by sulfhydryl groups. The yellow stain produced during the reduction is measured by spectrophotometry at $412 \mathrm{~nm}$. For measurement, a cocktail solution $[5.85 \mathrm{~mL}$ of $100-\mathrm{mM} \mathrm{Na}-$ phosphate buffer, $2.8 \mathrm{~mL}$ of $1-\mathrm{mM}$ DTNB $3.75 \mathrm{~mL}$ of 1-mM Nicotinamide adenine dinucleotide phosphate (NADPH), and $80 \mu \mathrm{L}$ of $625-\mathrm{U} / \mathrm{L}$ glutathione reductase] was prepared. Before measurement, $0.1 \mathrm{~mL}$ of meta-phosphoric acid was added onto $0.1 \mathrm{~mL}$ of tissue homogenate and centrifuged for 2 $\mathrm{min}$ at $2000 \mathrm{rpm}$ for deproteinization. Then, $0.15 \mathrm{~mL}$ of the cocktail solution was added to $50 \mu \mathrm{L}$ of the supernatant. The standard curve was obtained using glutathione disulfide (GSSG).

\section{Troponin I measurement:}

Troponin I levels in the plasma obtained from the animals were measured by enzyme-linked 
fluorescent assay using the VIDAS Troponin I Ultra kit. Readily available test reagents in the kit were used to automatically perform all steps of the test in the VIDAS equipment. The sample was transferred to the well containing alkaline phosphatase (conjugate)-labeled anti-cardiac troponin I antibodies. Sample-conjugate mix was placed in the solid phase receptacle to ensure the binding of the antigen to the conjugate and troponin I, which is bound to the inner wall of the solid phase receptacle. The unbound content was washed away. The conjugated enzyme catalyzes the hydrolysis of 4methyl umbelliferyl phosphate (the substrate) to 4-methylumbelliferone, whose fluorescence is measured at $450 \mathrm{~nm}$. The fluorescence intensity is directly proportional to the antigen concentration in the sample.

\section{CK measurement:}

Photometric measurement of the $\mathrm{CK}$ in the plasma obtained from the animals was performed using Roche/Hitachi Cobas c 701 system. Readily available test reagents were used to perform all steps of the test according to the procedure. UV test is per-formed according to the following reactions. Equimolar NADPH and ATP are produced at the same rate. The rate of NADPH formation, which is photometrically measured at $340 \mathrm{~nm}$, is directly proportional to the CK activity.

\section{$C K-M B$ measurement:}

Measurement of the CK-MB in the plasma obtained from the animals was performed using Roche/Hitachi Cobas c 701 system. Readily available test reagents were used to perform all steps of the test using immunological UV test, according to the procedure. CK-MB isoenzyme is composed of the two subunits CK-M and CK-B, both of which have an active site. With the help of CKM-specific antibodies, catalytic activities of the CK-M subunit in the sample are $99.6 \%$ inhibited without affecting the CK-B subunit. There maining CK-B activity, which is equivalent to the half of the CK-MB activity, is measured using total CK method.

\section{Results}

\section{1- Results of histological studies:}

Group I (Normal control): Light microscopic examination of rat heart specimens stained with haematoxylin and eosin stain showed normal architecture of myocardium; branching and anastomosing cardiac muscle fibers running in different directions with oval vesicular nuclei and acidophilic sarcoplasm. Small thin walled blood vessels and few spindle shaped nuclei of fibroblast in the interstitial tissue in-between could be observed (Figs. 1,2). Masson's trichrome stained sections of the same group visualized normal architecture of myocardium with minimal collagen deposition between myocardial fibers and around blood vessels (Fig. 3). Electron microscopic examination of rat heart specimens of the same group revealed numerous mitochondria $(\mathrm{m})$ with normal parallel cristal patteren between myofibrils alternating dark bands (D) and light bands (L) with regular $\mathrm{Z}$ lines inside and sarcomere $(S)$ between 2 successive $\mathrm{Z}$ lines (Fig. 4).

Group II (Doxorubicin administration): Light microscopic examination of rat heart specimens stained with haematoxylin and eosin stain showed: Completely degenerated myocardial fibers, markedly disturbed myocardial architecture with vacuolated sarcoplasm, markedly increased number of fibroblasts and ghost nuclei, and a small blood vessel could be observed (Figs. 5,6). Masson's trichrome stained sections of the same group visualized marked increase in collagen tissue deposition between myocardial fibers and around a markedly hypertrophied blood vessels and an extensively fibrosed segment of rat myocardium(Figs. 7,8). Electron microscopic examination of rat heart specimens of the same group revealed markedly disturbed myocardial architecture with extensive sarcoplasmic rarefaction Most of mitochondria appear ballooned with lost cristae. Disrupted myofibrils could be observed (Fig. 9).

Group III (Doxorubicin and spironolactone preadministration): Light microscopic examination of rat heart specimens stained with haematoxylin and eosin stain showed: Apparently normal branching pattern of myocardial fibers, normal vesicular oval nuclei, few fibroblasts with few areas of sarcoplasmic vacuolation could be seen (Fig. 10). Masson's trichrome stained sections of the same group visualized minimal increase in collagen tissue deposition between myocardial fibers and around a markedly congested blood vessel (Fig. 11).

Electron microscopic examination of rat heart specimens of the same group revealed apparently normal myocardial architecture; parallel myofibrils, alternating dark bands (D) and light bands (L) with regular $\mathrm{Z}$ lines inside and sarcomere $(\mathrm{S})$ between 2 successive $z$ lines. Most of mitochondria are apparently normal with intact cristae and few of them are ballooned with damaged cristae (Fig. 12).

Group IV (Doxorubicin and spironolactone Coadministration): Light microscopic examination 
of rat heart specimens stained with haematoxylin and eosin stain showed: Markedly increased fibroblasts and ghost nuclei, sarcoplasmic vacuolation, congested blood vessel and mononuclear cell infiltration could be observed (Figs. 13,14). Masson's trichrome stained sections of the same group visualized moderate increase in collagen tissue deposition between myocardial fibers and around a markedly congested blood vessel (Fig. 15).

Electron microscopic examination of rat heart specimens of the same group revealed disrupted myofibrils, sarcoplasmic rarefaction and ballooned mitochondria with damaged cristae (Fig. 16).

Group V (Doxorubicin and spironolactone Postadministration): Light microscopic examination

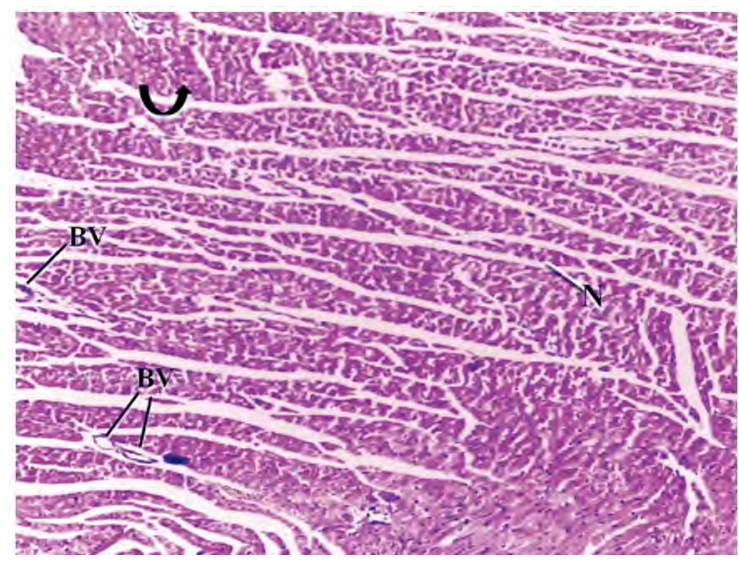

Fig. (1): A photomicrograph of a section of a rat myocardium from group I (Normal control) showing normal architecture of myocardium; branching and anastomosing cardiac muscle fibers (curved arrow) running in different directions with oval vesicular nuclei $(\mathrm{N})$ and acidophilic sarcoplasm. Small thin walled blood vessels can be observed (BV) (H\&E X200).

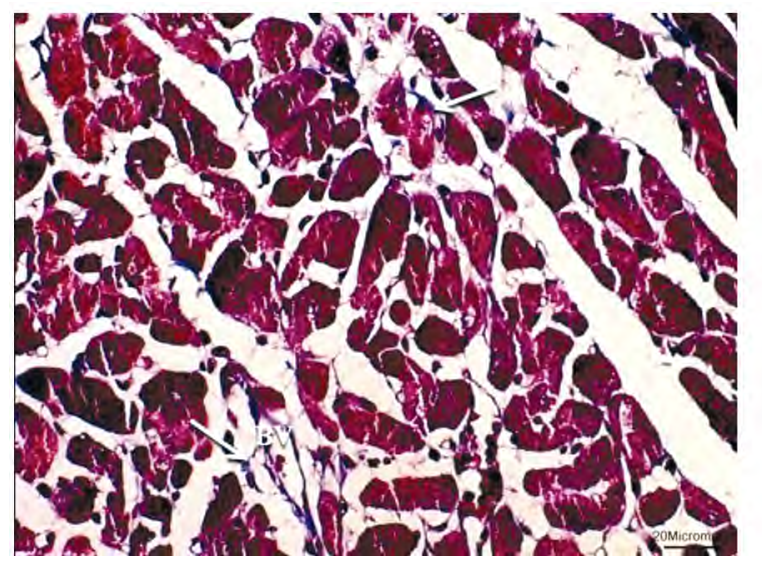

Fig. (3): A photomicrograph of a section of a rat myocardium from group I displaying normal architecture of myocardium with minimal collagen deposition (arrow) between myocardial fibers and around blood vessels (BV) (Masson's trichrome $\mathrm{x}$ 400). of rat heart specimens stained with haematoxylin and eosin stain showed: Markedly disturbed myocardial architecture with vacuolated sarcoplasm, markedly increased number of fibroblasts and ghost nuclei could be observed (Fig. 17). Masson's trichrome stained sections of the same group visualized moderate increase in collagen tissue deposition between myocardial fibers and around a markedly congested thickened blood vessel and an extensively fibrosed segment of rat myocardium (Figs. 18, 19). Electron microscopic examination of rat heart specimens of the same group revealed markedly disturbed myocardial architecture with extensive sarcoplasmic rarefaction. Most of mitochondria appear ballooned with lost cristae that might be huge in many specimens. Disrupted myofibrils could be observed (Figs. 20,21).

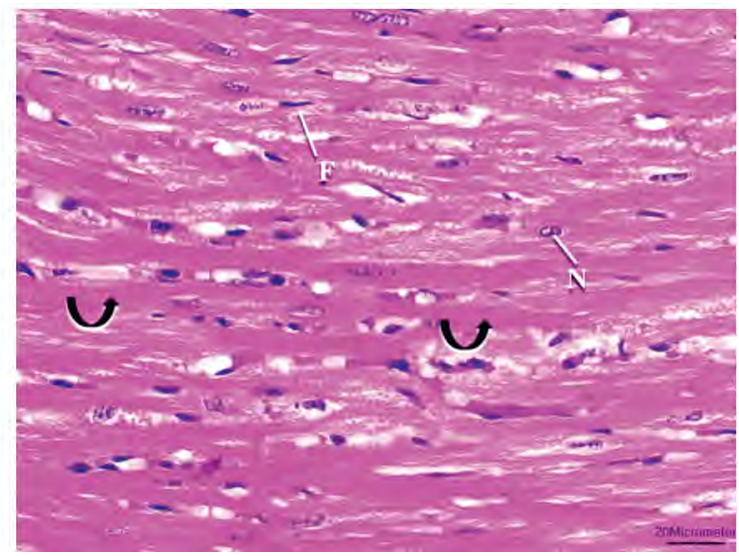

Fig. (2): A photomicrograph of a section of a rat myocardium from group I showing normal architecture of myocardium; branching and anastomosing cardiac muscle fibers (curved arrow) running in different directions with oval vesicular nuclei $(\mathrm{N})$ and acidophilic sarcoplasm. Few spindle shaped nuclei of fibroblast in the interstitial tissue in-between (F) can be observed (H\&E X400).

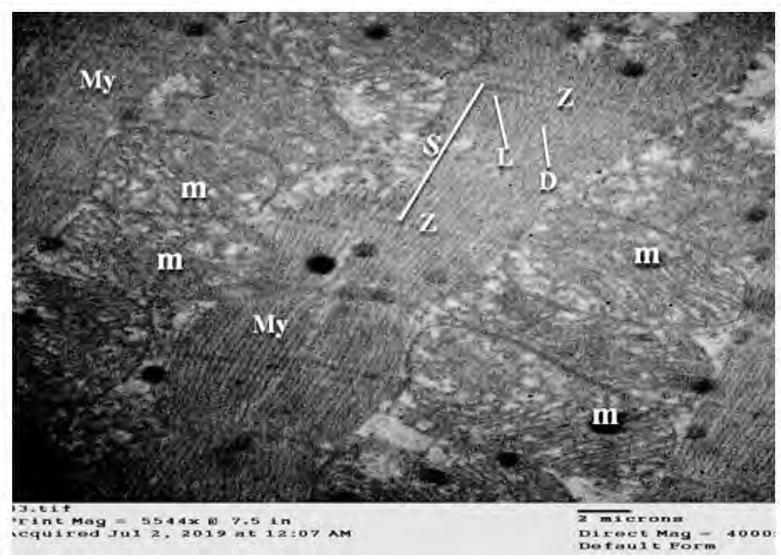

Fig. (4): An electron micrograph of a section of rat myocardium from group I showing numerous mitochondria (m) with normal parallel cristal patteren between myofibrils (My) alternating dark bands (D) and light bands (L) with regular $\mathrm{Z}$ lines inside and sarcomere (S) between 2 successive $\mathrm{z}$ lines (TEM x4000). 


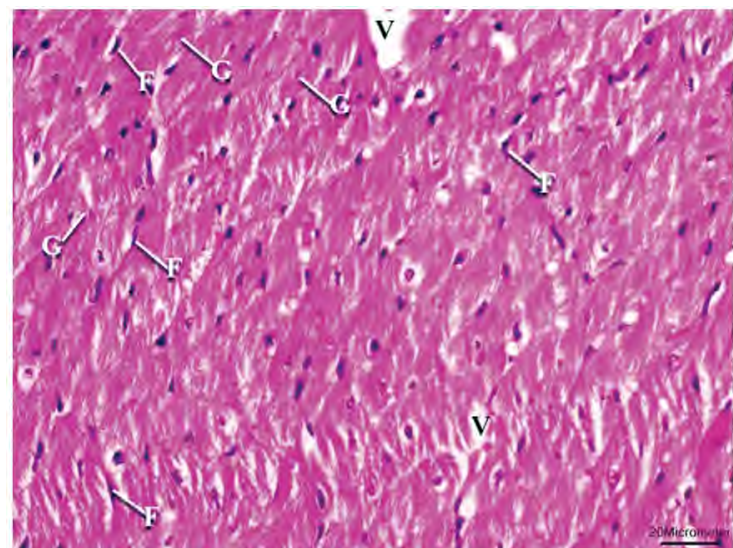

Fig. (5): A photomicrograph of a section of a rat myocardium from group II (Doxorubicin adminstraion) showing markedly disturbed myocardial architecture with vacuolated sarcoplasm (V), markedly increased number of fibroblasts (F) and ghost (G) nuclei can be observed (H\&E X400).

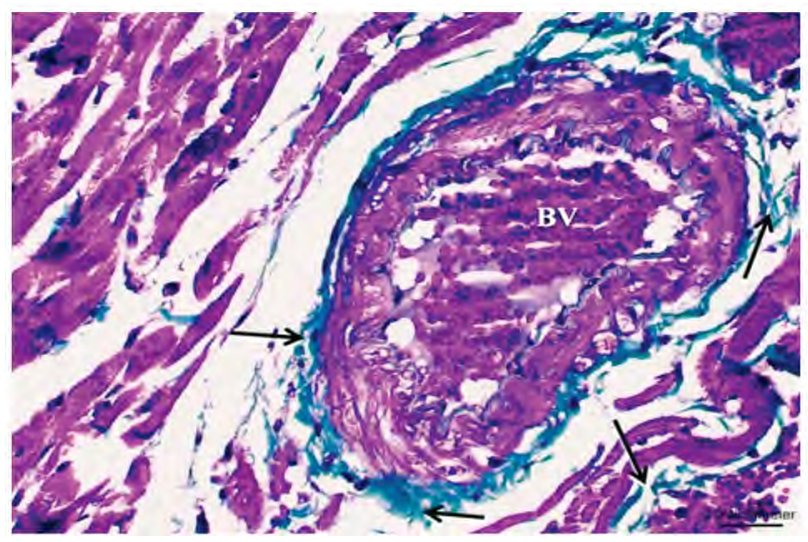

Fig. (7): A photomicrograph of a section of a rat myocardium from group II displaying marked increase in collagen tissue deposition (arrow) between myocardial fibers and around a markedly hypertrophied blood vessels (BV) (Masson's trichrome $\mathrm{x} 400$ ).

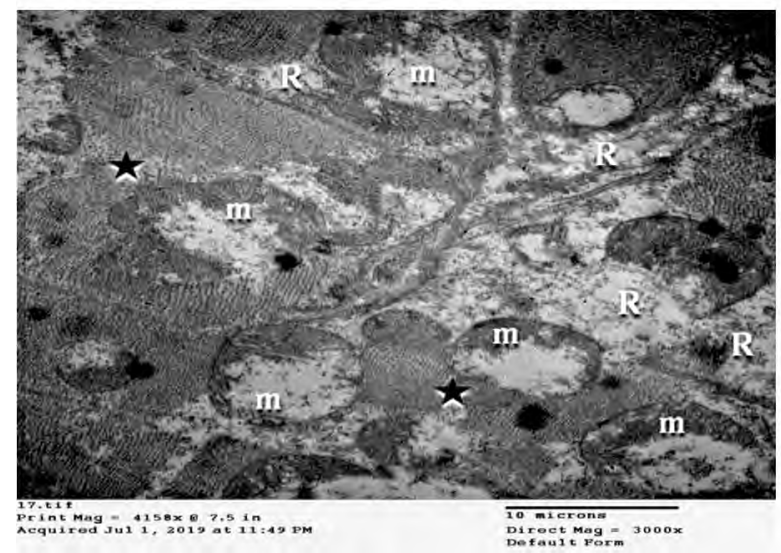

Fig. (9): An electron micrograph of a section of a rat myocardium from group II showing markedly disturbed myocardial architecture with extensive sarcoplasmic rarefaction (R). Most of mitochondria appear ballooned with lost cristae (m). Disrupted myofibrils (star) can be observed (TEM x3000).

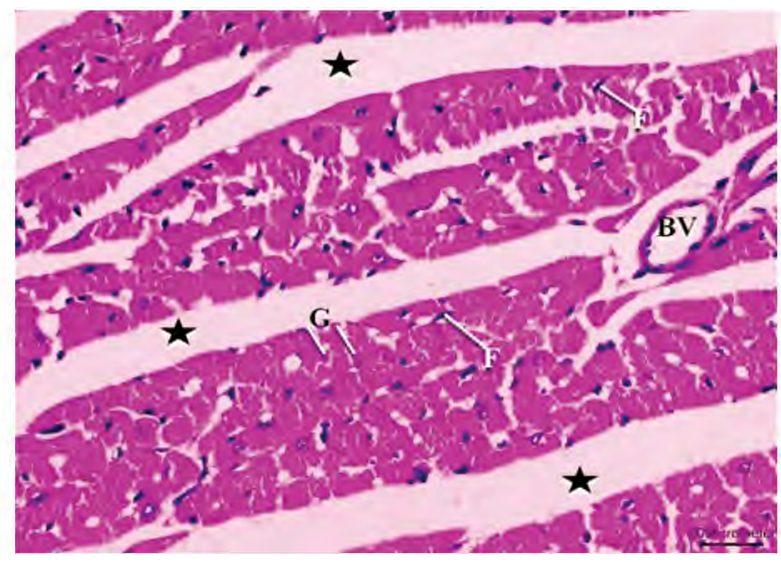

Fig. (6): A photomicrograph of a section of a rat myocardium from group II showing completely degenerated myocardial fibers (star), markedly increased number of fibroblasts (F) and ghost (G) nuclei. A small blood vessel can be observed (H\&E X400).

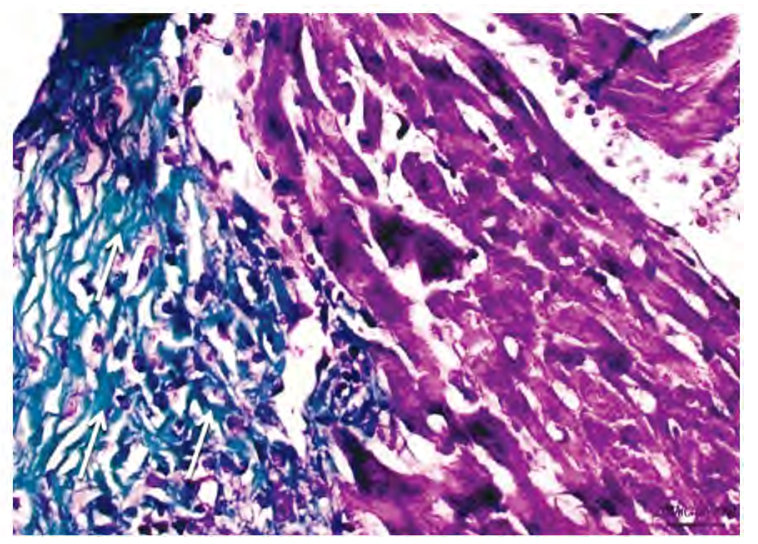

Fig. (8): A photomicrograph of a section from group II displaying an extensively fibrosed segment of rat myocardium (arrows) (Masson's trichrome x 400).

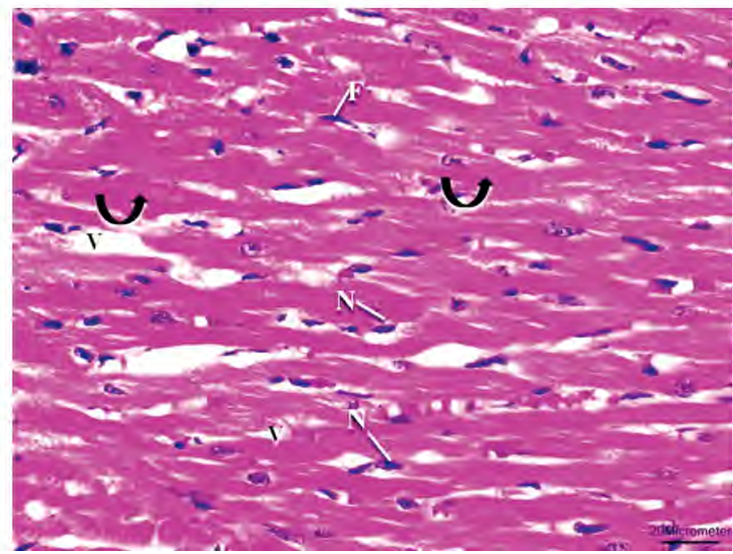

Fig. (10): A photomicrograph of a section of a rat myocardium from group III (Doxorubicin and spironolactone pre-administration) showing apparently normal branching pattern of myocardial fibers (curved arrow), normal vesicular oval nuclei $(\mathrm{N})$, few fibroblasts $(\mathrm{F})$ with few areas of sarcoplasmic vacuolation (V) can be seen. 


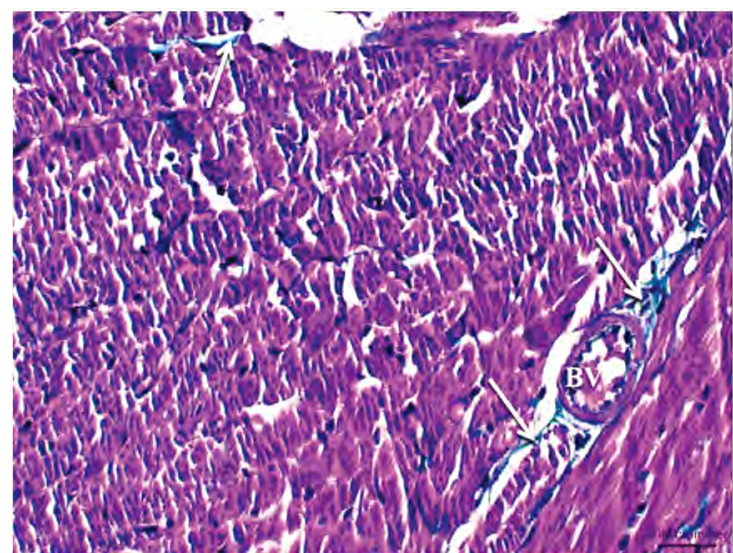

Fig. (11): A photomicrograph of a section of a rat myocardium from group III displaying minimal increase in collagen tissue deposition (arrow) between myocardial fibers and around a markedly congested blood vessel (BV) (Masson's trichrome x 400).

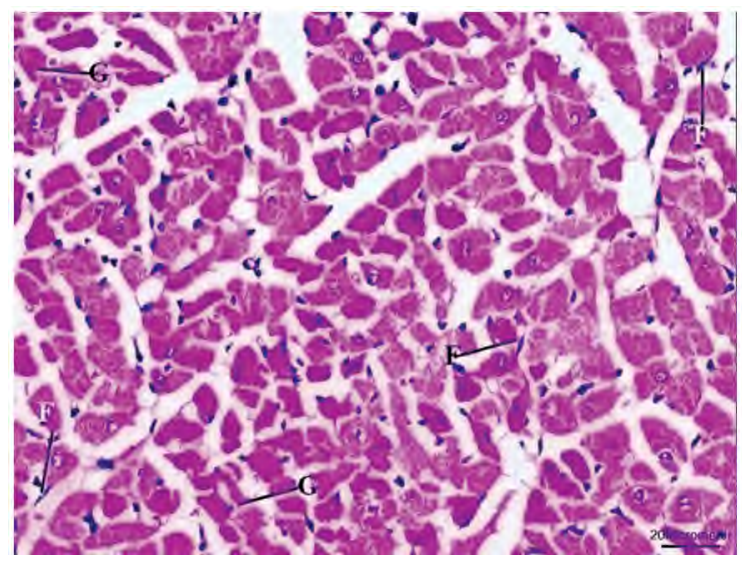

Fig. (13): A photomicrograph of a transverse section of a rat myocardium from group IV (Doxorubicin and spironolactone co-administration): Showing markedly increased fibroblasts (F) and ghost nuclei (G). (H\&E X400).

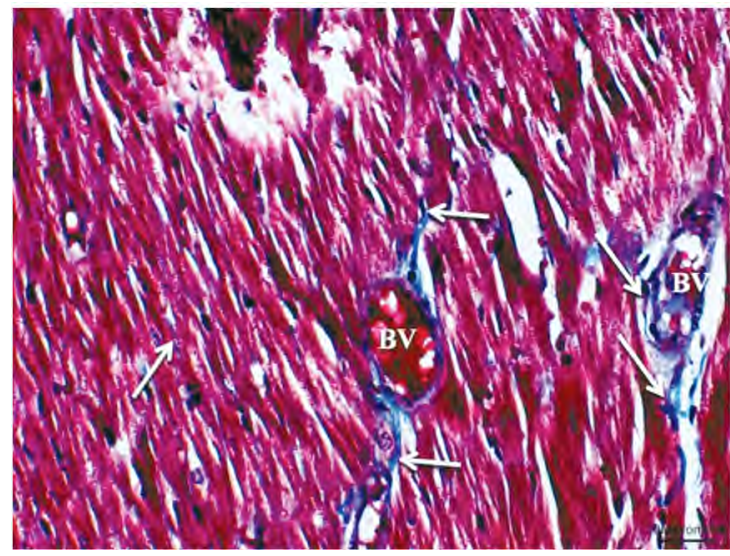

Fig. (15): A photomicrograph of a section of a rat myocardium from group IV displaying moderate increase in collagen tissue deposition (arrow) between myocardial fibers and around a markedly congested blood vessel (BV) (Masson's trichrome $\mathrm{x} 400$ ).

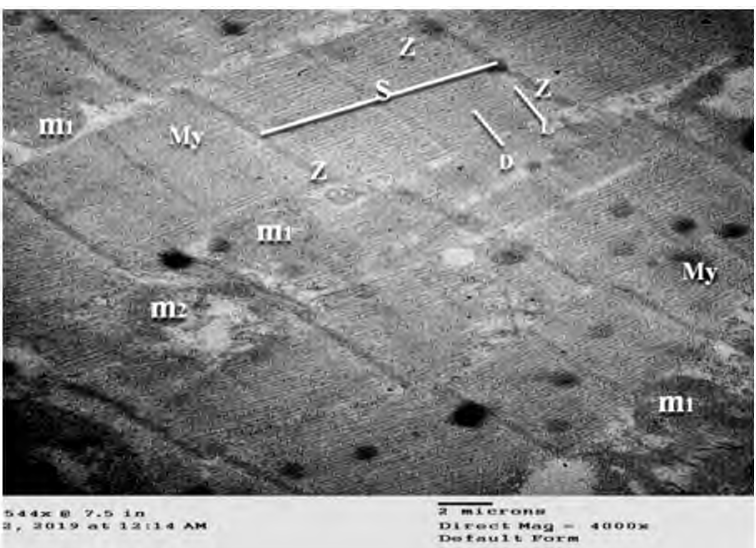

Fig. (12): An electron micrograph of a section of a rat myocardium from group III showing apparently normal myocardial architecture; parallel myofibrils (My), alternating dark bands (D) and light bands (L) with regular Z lines inside and sarcomere $(S)$ between 2 successive $z$ lines Most of mitochondria are apparently normal with intact cristae $(\mathrm{m} 1)$ and few of them (m2) are ballooned with damaged cristae (TEM x4000).

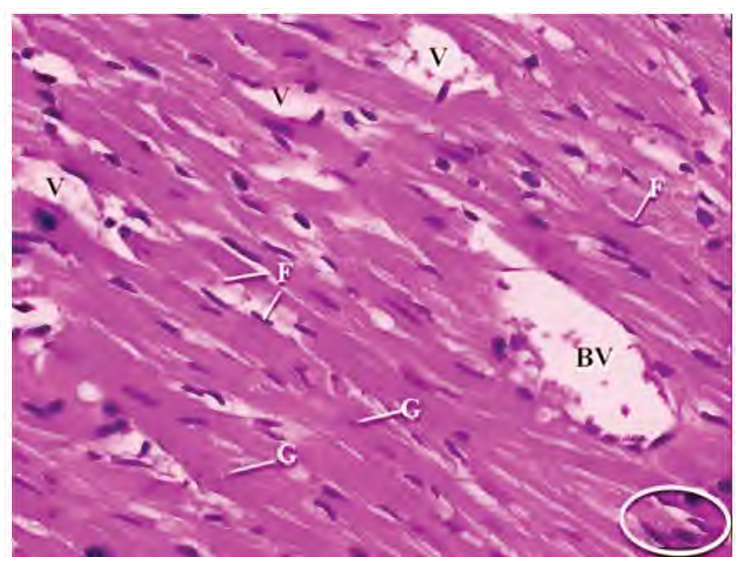

Fig. (14): A photomicrograph of a transverse section of a rat myocardium from group IV: Showing markedly increased fibroblasts (F), ghost nuclei $(\mathrm{G})$, sarcoplasmic vacuolation (V), congested blood vessel (BV) and mononuclear cell infiltration (Circle) can be observed. (H\&E X400).

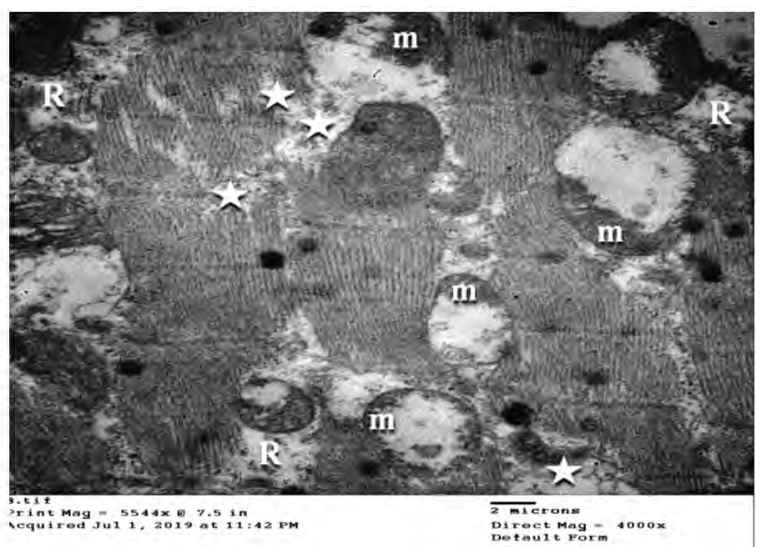

Fig. (16): An electron micrograph of a section of a rat myocardium from group IV showing disrupted myofibrils (star), sarcoplasmic rarefaction (R) and ballooned mitochondria (m) with damaged cristae. (TEM X4000). 


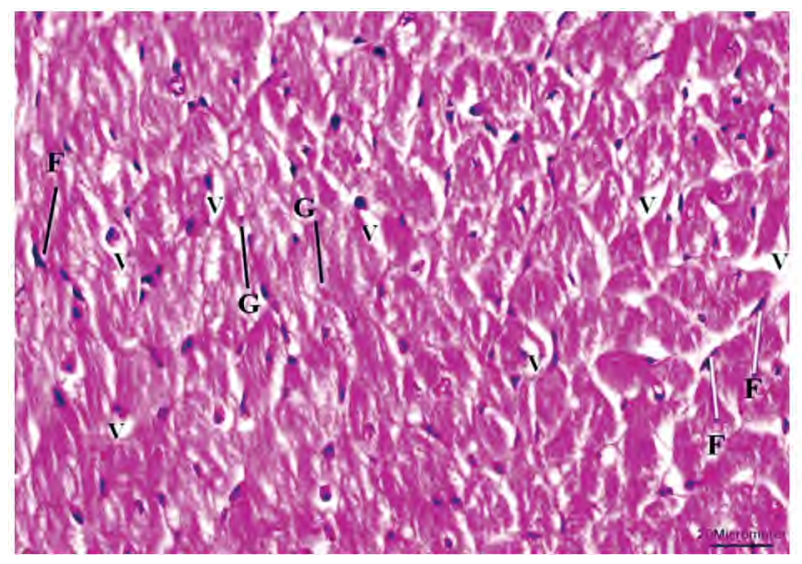

Fig. (17): A photomicrograph of a section of a rat myocardium from group V (Doxorubicin and spironolactone Postadministration) showing markedly disturbed myocardial architecture with vacuolated sarcoplasm (V), markedly increased number of fibroblasts $(F)$ and ghost $(G)$ nuclei can be observed (H\&E X400).

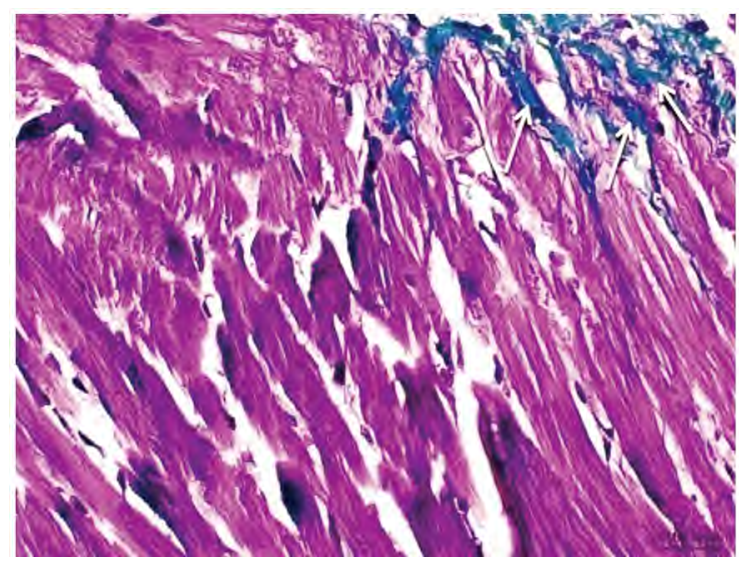

Fig. (19): A photomicrograph of a section from group $\mathrm{V}$ displaying an extensively fibrosed segment of rat myocardium (arrows) (Masson's trichrome x 400).

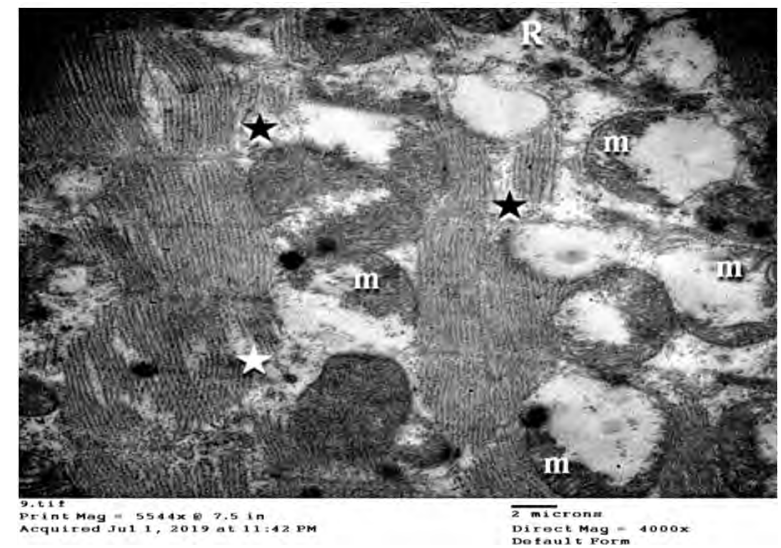

Fig. (21): An electron micrograph of a section of a rat myocardium from group $\mathrm{V}$ showing huge mitochondria with lost cristae (m), markedly disturbed myocardial architecture with extensive sarcoplasmic rarefaction (R). Disrupted myofibrils (star) can be observed (TEM x4000).

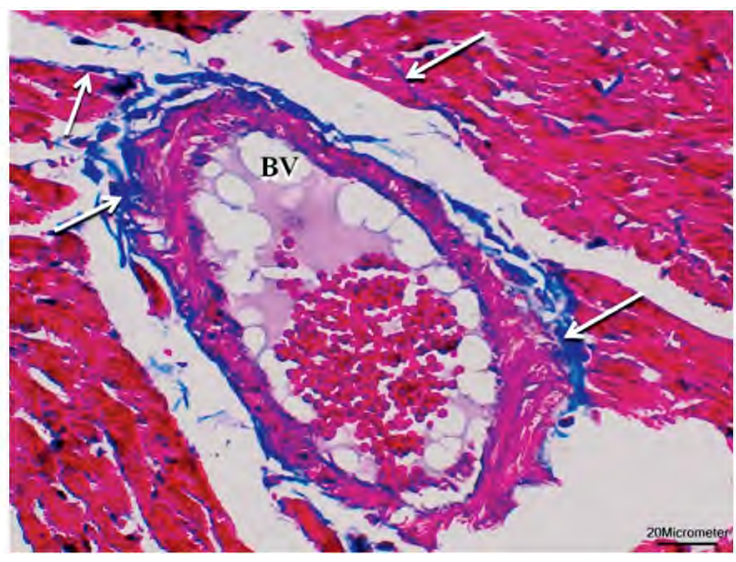

Fig. (18): A photomicrograph of a section of a rat myocardium from group $\mathrm{V}$ displaying moderate increase in collagen tissue deposition (arrow) between myocardial fibers and around a markedly congested thickened blood vessel (BV) (Masson's trichrome x 400).

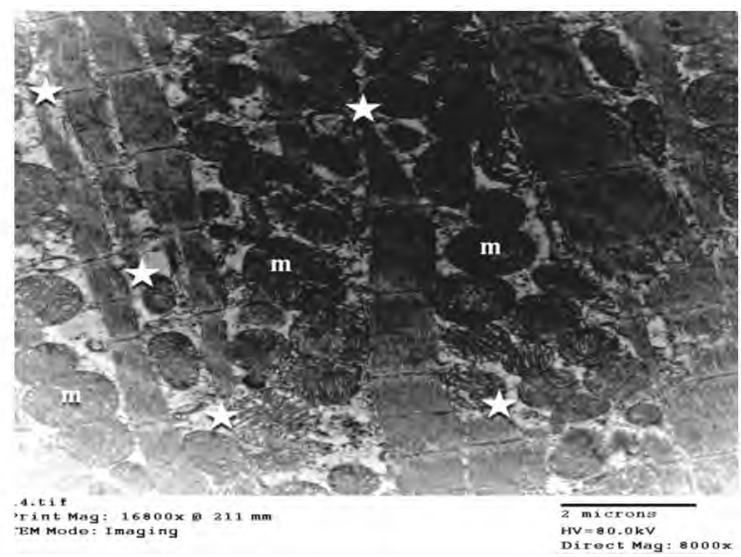

Fig. (20): An electron micrograph of a section of a rat myocardium from group $\mathrm{V}$ showing markedly disturbed myocardial architecture with extensive sarcoplasmic rarefaction (R) Most of mitochondria appear ballooned with lost cristae (m). Disrupted myofibrils (star) can be observed (TEM x8000).

\section{Statistical analysis of data:}

The collected data was organized, tabulated and statistically analyzed using SPSS software statistical computer package version 22 (SPSS Inc, USA). The mean and standard deviation (SD) were calculated. One way ANOVA (Analysis of variance) was used to test the difference about mean values of measured variables among groups, multiple comparison between pairs of groups were performed using Tukey HSD (Post hoc range test). For interpretation of results of tests of significance, significance was adopted at $p \leq 0.05$.

Collagen area \% was statistically significantly higher in group II $(12.99 \pm 1.9)$, IV $(7.8 \pm 0.87)$, and

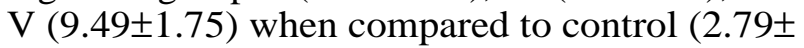


0.9), $p<0.0001$. However, the difference between group III and control was not a statistically significant, $p=0.096$. Collagen area $\%$ was a statistically significantly lower in groups; III (5.02 \pm 0.73$)$, IV (7.8 \pm 0.87$)$, and V $(9.49 \pm 1.75)$ as compared to group II (12.99 \pm 1.9$), p<0.0001, p<00001$ and $p=0.004$, respectively. As well as, it was statistically significantly higher in group IV (7.8 \pm 0.87$)$, and $\mathrm{V}(9.49 \pm 1.75)$ when compared to group III (5.02 $\pm 0.73), p=0.026$ and $p<0.0001$, respectively. There was no a statistically significant difference between the group IV and group V ( $p=0.294)$ (Figs. 22,23).

SOD was statistically significantly lower in group II (1.26 \pm 0.49$)$, IV (2.66 \pm 0.5$)$, and V (1.53 \pm $0.65)$ when compared to control $(4.17 \pm 0.43)$, $p<0.0001, p=0.001$, and $p<0.0001$, respectively. Conversely, the difference between group III and control was not a statistically significant, $p=0.125$. Likewise, SOD was a statistically significantly lower in both groups; III (3.37 \pm 0.43$)$ and IV (2.66 $\pm 0.5)$ as compared to group II (1.26 \pm 0.49$)$, $p<0.0001$ and $p=0.002$, respectively. But, there was no a statistically significantly difference between group V and group II, $p=0.913$. Also, it was statistically significantly higher in group V (1.53 $\pm 0.65)$ as compared to group III $(3.37 \pm 0.43)$, $p<0.0001$. However, there was no a statistically significant difference between the group IV and group III $(p=0.218)$. There was a statistically significant difference between the group IV and group $\mathrm{V}(p=0.016)$ (Figs. 24,25).

GSH was a statistically significantly lower in group II (21.23 \pm 3.56$)$, III (40.54 \pm 8.33$)$, and V

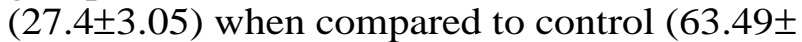
$5.42), p<0.0001$. In opposition, the difference between group III and control was not a statistically significant, $p=0.222$. However, it was a statistically significantly higher in both groups; III (55.92 5.32), and IV (40.54 \pm 8.33$)$ as compared to group II $(21.23 \pm 3.56), p<0.0001$. There was no a statistically significantly difference between group $\mathrm{V}$ and group II, $p=0.408$. On the other hand, it was statistically significantly higher in group IV (40.54 $\pm 8.33)$ and $\mathrm{V}(27.4 \pm 3.05)$ as compared to group III (55.92 \pm 5.32$), p=0.002$ and $p<0.0001$, respectively. Also, there was a statistically significant difference between the group IV and group V $(p=0.009)$ (Figs. 26,27).

MDA was statistically significantly higher in group II (69.41 \pm 11.89$)$, IV (47.79 \pm 6.03$)$, and V

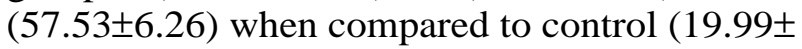
$7.81), p<0.0001$. However, the difference between group III and control was not a statistically significant, $p=0.054$. MDA was a statistically significant- ly lower in groups; III (34.35 \pm 4.06$)$, and IV (57.53 $\pm 6.26)$ as compared to group II (69.41 \pm 11.89$)$, $p<0.0001$ and $p=0.002$, respectively. But, there was a no statistically significantly difference between group $\mathrm{V}$ and group II, $p=0.143$. Also, it was statistically significantly higher group V (57.53 $6.26)$ when compared to group III $(34.35 \pm 4.06)$, $p=0.001$. However, there was no a statistically significant difference between the group IV versus group III ( $p=0.078)$ and group V $(p=0.299)$ (Figs. $28,29)$.

CK was statistically significantly higher in group II (1008 \pm 87.85$)$, IV (619.8 \pm 33.57$)$, and V (647.4 \pm 79.86$)$ when compared to control (427.8 \pm 54.1), $p<0.0001, p=0.002$, and $p=0.001$, respectively. However, the difference between group III and control was not a statistically significant, $p=0.929$. CK was a statistically significantly lower in groups;

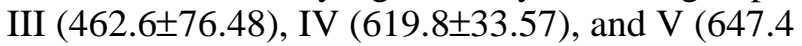
$\pm 79.86)$ as compared to group II (1008 \pm 87.85$)$, $p<0.0001$. Also, it was statistically significantly higher in group IV (619.8 \pm 33.57$)$, and V (647.4 \pm 79.86) when compared to group III (462.6 \pm 76.48$)$, $p=0.014$ and $p=0.003$, respectively. However, there was no a statistically significant difference between the group IV versus group V $(p=0.968)$ (Figs. $30,31)$.

CK-MB was statistically significantly higher in group II (423.2 \pm 165.71$)$, when compared to control (149 \pm 35.1$), p=0.001$. Also, itwas a statistically significantly lower in groupsIII (208.6 \pm 14.6), $p=0.009$. But, there was no a statistically significantly differences in CK-MBbetween other groups $(p>0.050)$ (Figs. 32,33).

Troponin I was statistically significantly higher in group II (73.6 \pm 10.88$)$, IV $(54 \pm 5.87)$, and V (65.4 \pm 13.96$)$ when compared to control (22.2 \pm $9.52), p<0.0001$. However, the difference between group III and control was not a statistically significant, $p=0.317$. Troponin I was also a statistically significantly lower in groups; III (34.4 \pm 6.54$)$, IV (54 \pm 5.87$)$, as compared to group II (73.6 \pm 10.88$)$, $p<0.0001$ and $p=0.035$, respectively. However, there was no a statistically significant difference between the group V versus group II ( $p=0.681)$. Also, it was statistically significantly higher in group IV (54 \pm 5.87$)$, and V (65.4 \pm 13.96$)$ versus group III (34.4 \pm 6.54$), p=0.035$ and $p=0.001$, respectively. However, there was no a statistically significant difference between the group IV versus group V ( $p=0.381)$ (Figs. 34,35).

TNF alpha was statistically significantly higher in group II (8.98 \pm 1.02$)$, IV (4.95 \pm 1.21$)$, and V 
(5.85 \pm 1.8$)$ when compared to control $(2.41 \pm 0.49)$, $p<0.0001, p=0.017$ and $p=0.001$, respectively. However, the difference between group III and control was not a statistically significant, $p=0.832$. TNF alpha was also a statistically significantly lower in groups; III (3.17 \pm 0.75$)$, IV (4.95 \pm 1.21$)$, and $\mathrm{V}(5.85 \pm 1.8)$, as compared to group II (8.98 $\pm 1.02), p<0.0001, p<0.0001$ and $\mathrm{p}=0.003$, respectively. Also, it was statistically significantly higher in group V $(5.85 \pm 1.8)$ versus group III $(3.17 \pm$ $0.75), p=0.011$. However, there was no a statistically significant difference between the group $\mathrm{V}$ versus group III $(p=0.140)$. However, there was no a statistically significant difference between the group IV versus group V ( $p=0.726)$ (Figs. 36,37).

IL-1b was statistically significantly higher in group II (6.72 \pm 1.3$)$, IV (3.96 \pm 0.99$)$, and V (5.6 \pm 1.62) when compared to control (1.5 \pm 0.27$)$, $p<0.0001, p=0.014, p<0.0001$, respectively. However, the difference between group III and control was not a statistically significant, $p=0.521$. IL- $1 \mathrm{~b}$ was also a statistically significantly lower in groups; III (2.59 \pm 0.69$)$, IV (3.96 \pm 0.99$)$, as compared to group II (6.72 \pm 1.3$), p<0.0001$ and $p=0.005$, respectively. However, there was no a statistically significant difference between the group V versus group
II $(p=0.489)$. Also, it was statistically significantly higher in group V (5.6 \pm 1.62$)$ versus group III (2.59 $\pm 0.69), p=0.002$. But, there was no a statistically significant difference between the group IV versus group III $(p=0.300)$. As well as, there was no a statistically significant difference between the group IV versus group V ( $p=0.157)$ (Figs. 38,39).

e NO was statistically significantly lower in group II (39.2 \pm 13.97$)$, IV (64.4 \pm 11.8$)$, and V (49.4 \pm 11.41) when compared to control (101.2 \pm 15.01$)$, $p<0.0001, p=0.001, p<0.0001$, respectively. But, there was no a statistically significant difference between group III and control, $p=0.362$. It was also a statistically significantly higher in groups; III (86.2 \pm 10.52$)$, IV (64.4 \pm 11.8$)$, as compared to group II (39.2 \pm 13.97$), p<0.0001$ and $p=0.036$, respectively. However, there was no a statistically significant difference between the group $\mathrm{V}$ versus group II $(p=0.709)$. Also, it was statistically significantly lower in group V $(49.4 \pm 11.41)$ versus group III (86.2 \pm 10.52$), p=0.001$. But, there was no a statistically significant difference between the group IV versus group III $(p=0.085)$. Also, there was no a statistically significant difference between the group IV versus group V $(p=0.362)$ (Figs. 40,41).

\begin{tabular}{|c|c|c|c|c|c|c|c|c|c|c|}
\hline & \multicolumn{2}{|c|}{ Group I (Control) } & \multicolumn{2}{|c|}{ Group II } & \multicolumn{2}{|c|}{ Group III } & \multicolumn{2}{|c|}{ Group IV } & \multicolumn{2}{|c|}{ Group V } \\
\hline & Mean & SD & Mean & SD & Mean & SD & Mean & SD & Mean & SD \\
\hline Collagen area $\%$ & 2.79 & 0.9 & 12.99 & 1.9 & 5.02 & 0.73 & 7.8 & 0.87 & 9.49 & 1.75 \\
\hline $\begin{array}{l}p \text {-values } \\
\text { G I vs. G II } \\
\text { G I vs. G III } \\
\text { G I vs. G IV } \\
\text { G I vs. G V } \\
\text { G II vs. G III } \\
\text { G II vs. G IV } \\
\text { G II vs. G V } \\
\text { G III vs. G IV } \\
\text { G III vs. G V } \\
\text { G IV vs. G V }\end{array}$ & $\begin{array}{l}<0.0 \\
0.09 \\
<0.0 \\
<0.0\end{array}$ & $\begin{array}{l}(\mathrm{S}) \\
\mathrm{S}) \\
(\mathrm{S}) \\
(\mathrm{S})\end{array}$ & $\begin{array}{l}<0.0 \\
<0.0 \\
0.00\end{array}$ & & $\begin{array}{l}0.02 \\
<0.0\end{array}$ & & 0.2 & VS) & & \\
\hline
\end{tabular}

Fig. (22): A table illustrating area percent of collagen fibers in rat myocardium specimens obtained from different groups of the examined animals.

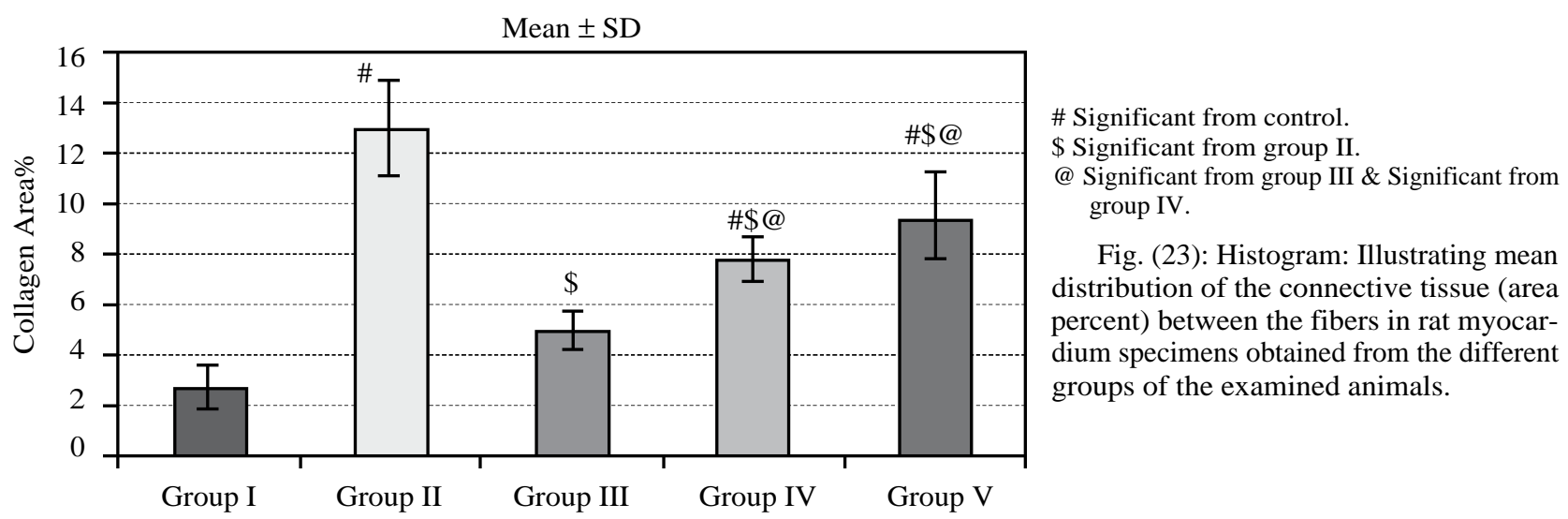




\begin{tabular}{|c|c|c|c|c|c|c|c|c|c|c|}
\hline & \multicolumn{2}{|c|}{ Group I (Control) } & \multicolumn{2}{|c|}{ Group II } & \multicolumn{2}{|c|}{ Group III } & \multicolumn{2}{|c|}{ Group IV } & \multicolumn{2}{|c|}{ Group V } \\
\hline & Mean & SD & Mean & SD & Mean & SD & Mean & SD & Mean & SD \\
\hline SOD & 4.17 & 0.43 & 1.26 & 0.49 & 3.37 & 0.43 & 2.66 & 0.5 & 1.53 & 0.65 \\
\hline $\begin{array}{l}\text { p-values } \\
\text { G I vs. G II } \\
\text { G I vs. G III } \\
\text { G I vs. G IV } \\
\text { G I vs. G V } \\
\text { G II vs. G III } \\
\text { G II vs. G IV } \\
\text { G II vs. G V } \\
\text { G III vs. G IV } \\
\text { G III vs. G V } \\
\text { G IV vs. G V }\end{array}$ & $\begin{array}{l}<0.0 \\
0.12 \\
0.00 \\
<0.0\end{array}$ & $\begin{array}{l}\text { (S) } \\
\text { IS) } \\
(\mathrm{S})\end{array}$ & $\begin{array}{l}<0.0 \\
0.00 \\
0.91\end{array}$ & $\begin{array}{l}(S) \\
\left.I_{S}\right)\end{array}$ & $\begin{array}{l}0.21 \\
<0.0\end{array}$ & $\begin{array}{l}\text { S) } \\
\text { (S) }\end{array}$ & & & & \\
\hline
\end{tabular}

Fig. (24): A table illustrating mean values of SOD in rat myocardium specimens obtained from different groups of the examined animals.

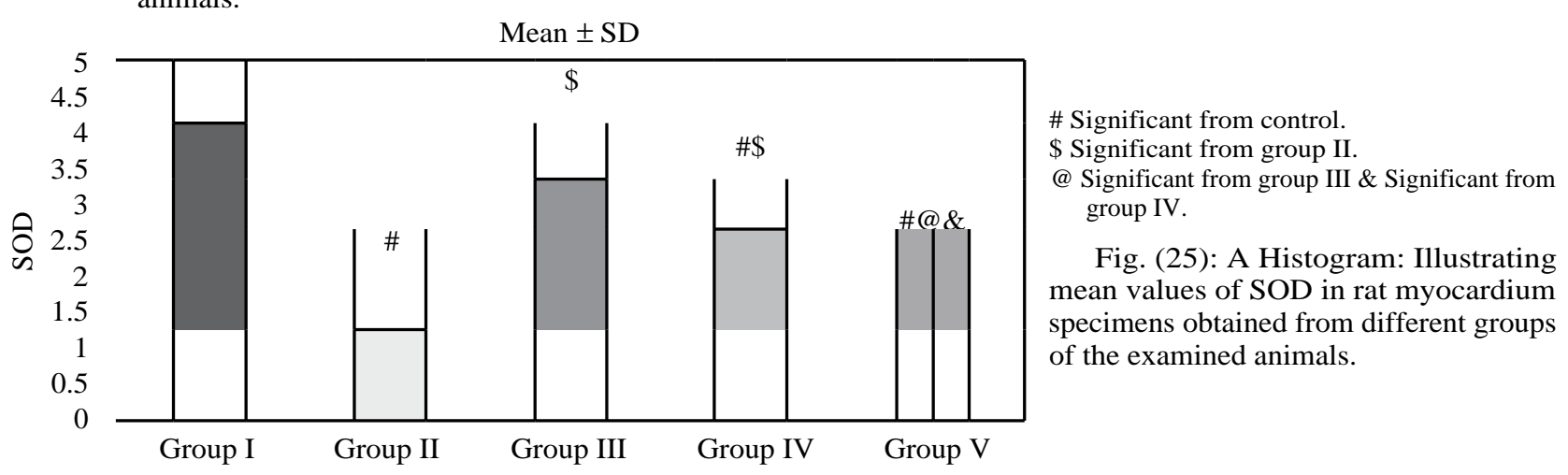

Glutathione Peroxidase (GSH):

\begin{tabular}{|c|c|c|c|c|c|c|c|c|c|c|}
\hline & \multicolumn{2}{|c|}{ Group I (Control) } & \multicolumn{2}{|c|}{ Group II } & \multicolumn{2}{|c|}{ Group III } & \multicolumn{2}{|c|}{ Group IV } & \multicolumn{2}{|c|}{ Group V } \\
\hline & Mean & SD & Mean & SD & Mean & SD & Mean & SD & Mean & SD \\
\hline GSH & 63.49 & 5.4 & 21.23 & 3.56 & 55.92 & 5.32 & 40.54 & 8.33 & 27.4 & 3.05 \\
\hline $\begin{array}{l}\text { p-values } \\
\text { G I vs. G II } \\
\text { G I vs. G III } \\
\text { G I vs. G IV } \\
\text { G I vs. G V } \\
\text { G II vs. G III } \\
\text { G II vs. G IV } \\
\text { G II vs. G V } \\
\text { G III vs. G IV } \\
\text { G III vs. G V } \\
\text { G IV vs. G V }\end{array}$ & $\begin{array}{l}<0.0 \\
0.22 \\
<0.0 \\
<0.0\end{array}$ & $\begin{array}{l}001(\mathrm{~S}) \\
2 \text { (NS) } \\
001 \text { (S) } \\
001 \text { (S) }\end{array}$ & $\begin{array}{l}<0.00 \\
<0.00 \\
0.408\end{array}$ & $\begin{array}{l}01(\mathrm{~S}) \\
01(\mathrm{~S}) \\
(\mathrm{NS})\end{array}$ & $\begin{array}{l}0.002 \\
<0.00\end{array}$ & $\begin{array}{l}\text { (S) } \\
01(\mathrm{~S})\end{array}$ & 0.00 & $99(\mathrm{~S})$ & & \\
\hline
\end{tabular}

Fig. (26): A table illustrating mean values of GSH in rat myocardium specimens obtained from different groups of the examined animals.

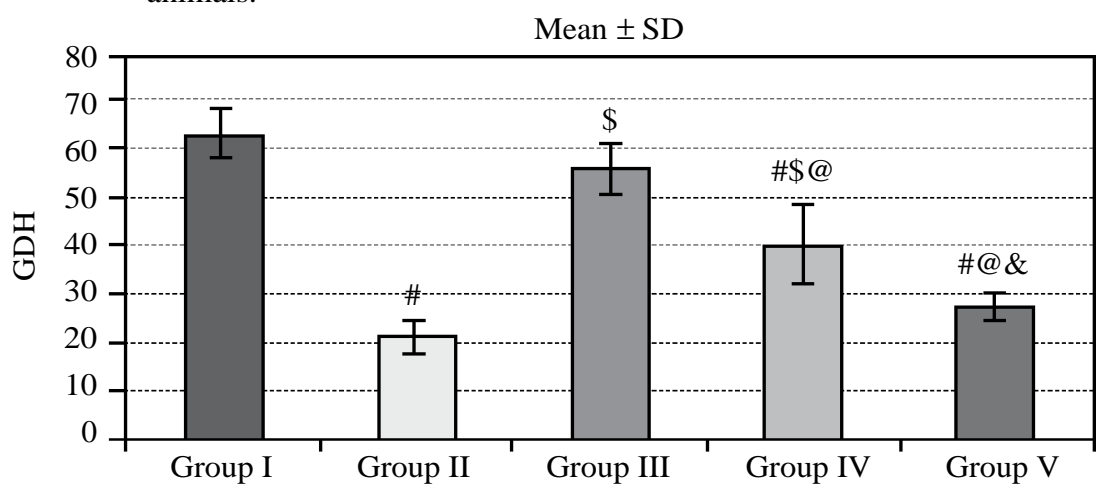

\# Significant from control.

$\$$ Significant from group II.

@ Significant from group III \& Significant from group IV.

Fig. (27): A Histogram: Illustrating mean values of GSH in rat myocardium specimens obtained from different groups of the examined animals. 


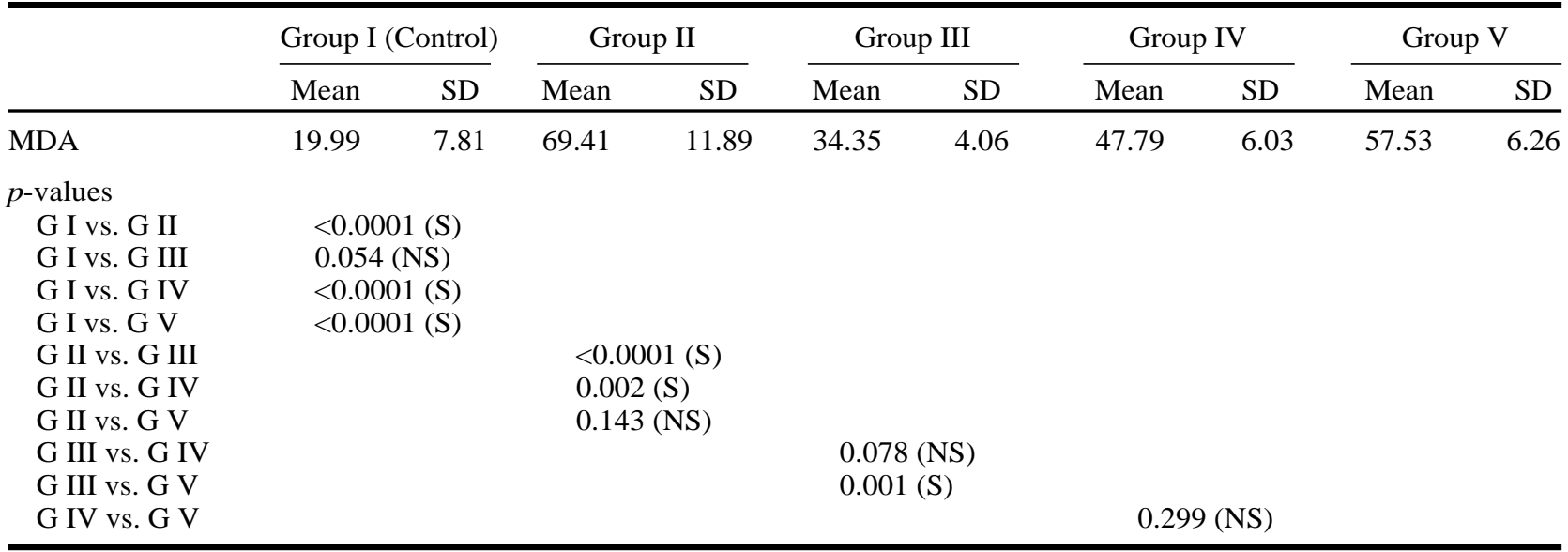

Fig. (28): A table illustrating mean values of MDA in rat myocardium specimens obtained from different groups of the examined animals.

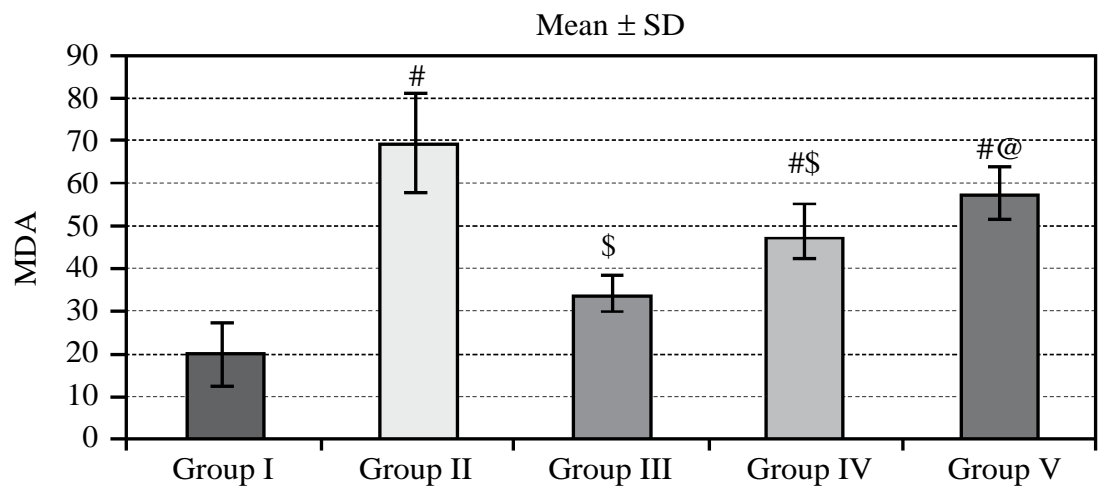

\# Significant from control.

$\$$ Significant from group II.

@ Significant from group III \& Significant from group IV.

Fig. (29): A Histogram: Illustrating mean values of MDA in rat myocardium specimens obtained from different groups of the examined animals.

\begin{tabular}{|c|c|c|c|c|c|c|c|c|c|c|}
\hline & \multicolumn{2}{|c|}{ Group I (Control) } & \multicolumn{2}{|c|}{ Group II } & \multicolumn{2}{|c|}{ Group III } & \multicolumn{2}{|c|}{ Group IV } & \multicolumn{2}{|c|}{ Group V } \\
\hline & Mean & SD & Mean & SD & Mean & SD & Mean & SD & Mean & SD \\
\hline CK & 427.8 & 54.1 & 1008 & 87.85 & 462.6 & 76.48 & 619.8 & 33.57 & 647.4 & 79.86 \\
\hline
\end{tabular}

$p$-values

$\begin{array}{ll}\text { G I vs. G II } & <0.0001(\mathrm{~S}) \\ \text { G I vs. G III } & 0.929(\mathrm{NS}) \\ \text { G I vs. G IV } & 0.002(\mathrm{~S}) \\ \text { G I vs. G V } & 0.001(\mathrm{~S})\end{array}$

G II vs. G III

$<0.0001(\mathrm{~S})$

G II vs. G IV

G II vs. G V

G III vs. G IV

G III vs. G V

G IV vs. G V

$0.014(\mathrm{~S})$

$0.003(\mathrm{~S})$

\section{$<0.0001(\mathrm{~S})$}

$<0.0001(\mathrm{~S})$

Fig. (30): A Table: Illustrating mean values of CK in rat myocardium specimens obtained from different groups of the examined animals.

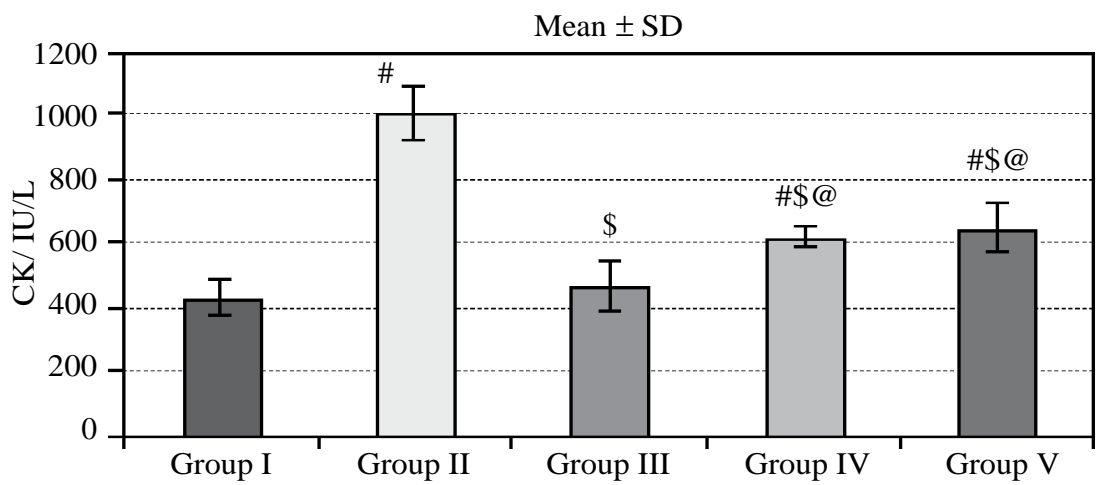

\# Significant from control.

$\$$ Significant from group II.

@ Significant from group III \& Significant from group IV.

Fig. (31): A Histogram: Illustrating mean values of $\mathrm{CK}$ in rat myocardium specimens obtained from different groups of the examined animals. 


\begin{tabular}{|c|c|c|c|c|c|c|c|c|c|c|}
\hline & \multicolumn{2}{|c|}{ Group I (Control) } & \multicolumn{2}{|c|}{ Group II } & \multicolumn{2}{|c|}{ Group III } & \multicolumn{2}{|c|}{ Group IV } & \multicolumn{2}{|c|}{ Group V } \\
\hline & Mean & SD & Mean & SD & Mean & SD & Mean & SD & Mean & SD \\
\hline CK-MB IU/L & 149 & 35.1 & 423.2 & 165.71 & 208.6 & 14.6 & 273.2 & 61.1 & 303.2 & 84.69 \\
\hline $\begin{array}{l}p \text {-values } \\
\text { G I vs. G II } \\
\text { G I vs. G III } \\
\text { G I vs. G IV } \\
\text { G I vs. G V } \\
\text { G II vs. G III } \\
\text { G II vs. G IV } \\
\text { G II vs. G V } \\
\text { G III vs. G IV } \\
\text { G III vs. G V } \\
\text { G IV vs. G V }\end{array}$ & $\begin{array}{l}0.0 \\
0.8 \\
0.2 \\
0.0\end{array}$ & $\begin{array}{l}\text { S) } \\
\text { NS) } \\
\text { NS) } \\
\text { NS) }\end{array}$ & $\begin{array}{l}0.00 \\
0.09 \\
0.24\end{array}$ & $\begin{array}{l}\text { (S) } \\
\text { (NS) } \\
\text { (NS) }\end{array}$ & $\begin{array}{l}0.78 \\
0.47\end{array}$ & & 0.98 & NS) & & \\
\hline
\end{tabular}

Fig. (32): A Table: Illustrating mean values of CK-MB in rat myocardium specimens obtained from different groups of the examined animals.

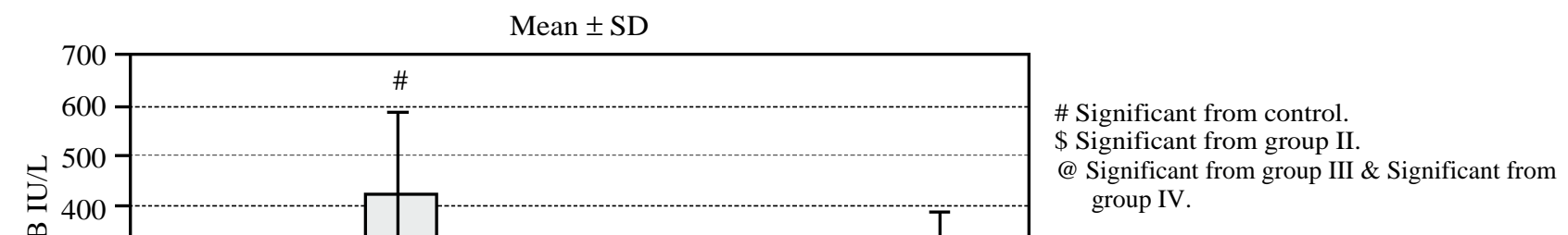

Fig. (33): A Histogram: Illustrating mean values of CK-MB in rat myocardium specimens obtained from different groups of the examined animals.

\begin{tabular}{|c|c|c|c|c|c|c|c|c|c|c|}
\hline & \multicolumn{2}{|c|}{ Group I (Control) } & \multicolumn{2}{|c|}{ Group II } & \multicolumn{2}{|c|}{ Group III } & \multicolumn{2}{|c|}{ Group IV } & \multicolumn{2}{|c|}{ Group V } \\
\hline & Mean & $\mathrm{SD}$ & Mean & SD & Mean & SD & Mean & $\mathrm{SD}$ & Mean & SD \\
\hline Troponin I pg/MI & 22.2 & 9.52 & 73.6 & 10.88 & 34.4 & 6.54 & 54 & 5.87 & 65.4 & 13.96 \\
\hline $\begin{array}{l}\text { p-values } \\
\text { G I vs. G II } \\
\text { G I vs. G III } \\
\text { G I vs. G IV } \\
\text { G I vs. G V } \\
\text { G II vs. G III } \\
\text { G II vs. G IV } \\
\text { G II vs. G V } \\
\text { G III vs. G IV } \\
\text { G III vs. G V } \\
\text { G IV vs. G V }\end{array}$ & $\begin{array}{l}<0.0 \\
0.31 \\
<0.0 \\
<0.0\end{array}$ & $\begin{array}{l}(\mathrm{S}) \\
\mathrm{IS}) \\
(\mathrm{S}) \\
(\mathrm{S})\end{array}$ & $\begin{array}{l}<0.0 \\
0.03 \\
0.68\end{array}$ & $\begin{array}{l}1(\mathrm{~S}) \\
\text { S) } \\
\mathrm{NS})\end{array}$ & $\begin{array}{l}0.0 \\
0.0\end{array}$ & & 0.38 & NS) & & \\
\hline
\end{tabular}

Fig. (34): A Table: Illustrating mean values of Troponin I in rat myocardium specimens obtained from different groups of the examined animals.

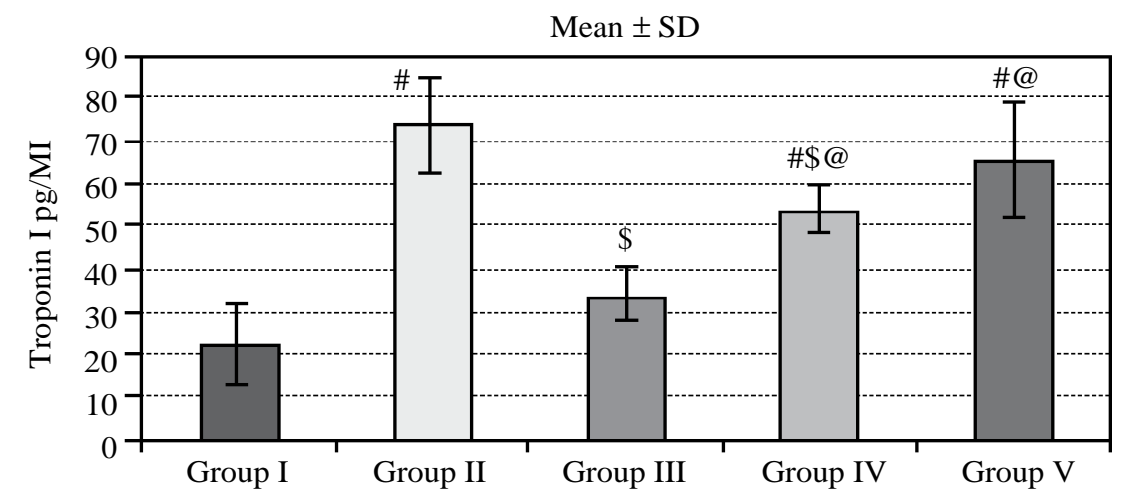

\# Significant from control.

$\$$ Significant from group II.

@ Significant from group III \& Significant from group IV.

Fig. (35): A Histogram: Illustrating mean values of Troponin 1 in rat myocardium specimens obtained from different groups of the examined animals. 
TNF alpha:

\begin{tabular}{|c|c|c|c|c|c|c|c|c|c|c|}
\hline & \multicolumn{2}{|c|}{ Group I (Control) } & \multicolumn{2}{|c|}{ Group II } & \multicolumn{2}{|c|}{ Group III } & \multicolumn{2}{|c|}{ Group IV } & \multicolumn{2}{|c|}{ Group V } \\
\hline & Mean & SD & Mean & $\mathrm{SD}$ & Mean & $\mathrm{SD}$ & Mean & $\mathrm{SD}$ & Mean & $\mathrm{SD}$ \\
\hline TNF Alpha & 2.41 & 0.49 & 8.98 & 1.02 & 3.17 & 0.75 & 4.95 & 1.21 & 5.85 & 1.8 \\
\hline $\begin{array}{l}p \text {-values } \\
\text { G I vs. G II } \\
\text { G I vs. G III } \\
\text { G I vs. G IV } \\
\text { G I vs. G V } \\
\text { G II vs. G III } \\
\text { G II vs. G IV } \\
\text { G II vs. G V } \\
\text { G III vs. G IV } \\
\text { G III vs. G V } \\
\text { G IV vs. G V }\end{array}$ & $\begin{array}{l}<0 . \\
0.83 \\
0.01 \\
0.00\end{array}$ & $\begin{array}{l}(\mathrm{S}) \\
\mathrm{NS}) \\
\mathrm{S}) \\
5)\end{array}$ & $\begin{array}{l}<0.0 \\
<0.0 \\
0.00\end{array}$ & $\begin{array}{l}\text { (S) } \\
\text { (S) }\end{array}$ & $\begin{array}{l}0.14 \\
0.01\end{array}$ & & 0.72 & VS) & & \\
\hline
\end{tabular}

Fig. (36): A Table: Illustrating mean values of TNF alpha in rat myocardium specimens obtained from different groups of the examined animals.

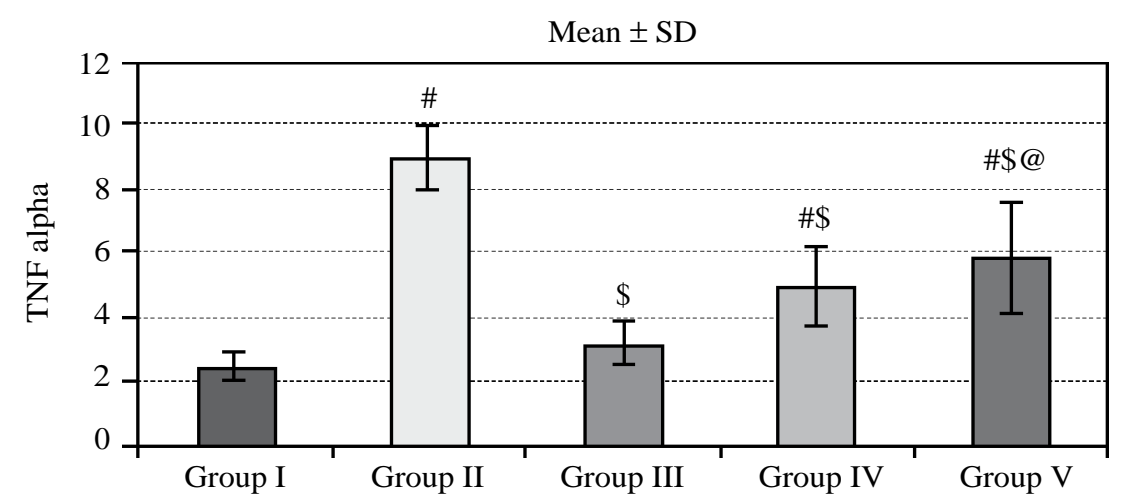

\# Significant from control.

$\$$ Significant from group II.

@ Significant from group III \& Significant from group IV.

Fig. (37): A Histogram: Illustrating mean values of TNF alpha in rat myocardium specimens obtained from different groups of the examined animals.

IL-1b:

\begin{tabular}{|c|c|c|c|c|c|c|c|c|c|c|}
\hline & \multicolumn{2}{|c|}{ Group I (Control) } & \multicolumn{2}{|c|}{ Group II } & \multicolumn{2}{|c|}{ Group III } & \multicolumn{2}{|c|}{ Group IV } & \multicolumn{2}{|c|}{ Group V } \\
\hline & Mean & SD & Mean & SD & Mean & $\mathrm{SD}$ & Mean & SD & Mean & SD \\
\hline IL-1b & 1.5 & 0.27 & 6.72 & 1.3 & 2.59 & 0.69 & 3.96 & 0.99 & 5.6 & 1.62 \\
\hline $\begin{array}{l}\text { p-values } \\
\text { G I vs. G II } \\
\text { G I vs. G III } \\
\text { G I vs. G IV } \\
\text { G I vs. G V } \\
\text { G II vs. G III } \\
\text { G II vs. G IV } \\
\text { G II vs. G V } \\
\text { G III vs. G IV } \\
\text { G III vs. G V } \\
\text { G IV vs. G V }\end{array}$ & $\begin{array}{l}<0.0 \\
0.52 \\
0.01 \\
<0.0\end{array}$ & $\begin{array}{l}(\mathrm{S}) \\
\mathrm{NS}) \\
\mathrm{S}) \\
(\mathrm{S})\end{array}$ & $\begin{array}{l}<0.0 \\
0.00 \\
0.48\end{array}$ & $\begin{array}{l}1(\mathrm{~S}) \\
\text { (S) } \\
\text { (NS) }\end{array}$ & $\begin{array}{l}0.3 \\
0.0\end{array}$ & $\begin{array}{l}\text { NS) } \\
\text { S) }\end{array}$ & 0.15 & NS) & & \\
\hline
\end{tabular}

Fig. (38): A Table: Illustrating mean values of IL-1b in rat myocardium specimens obtained from different groups of the examined animals.

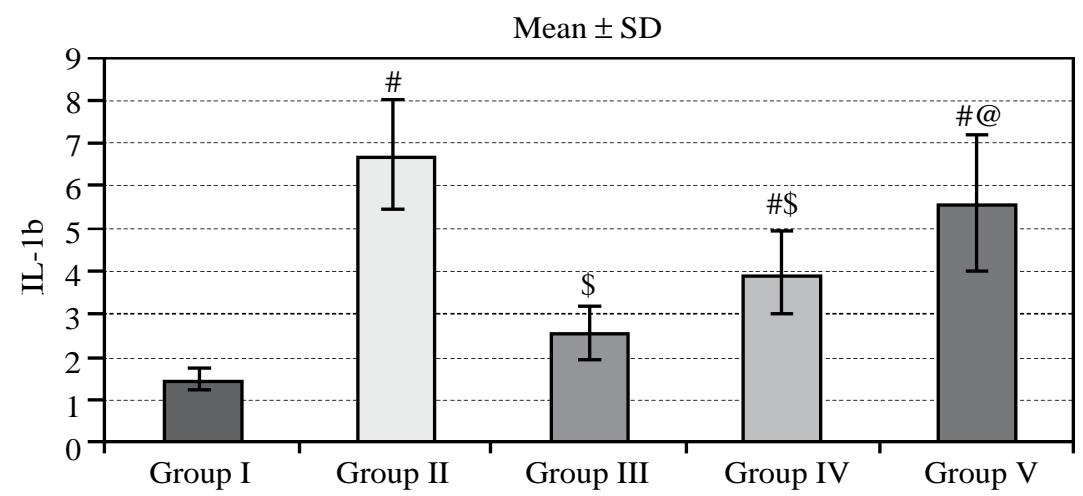

\# Significant from control.

\$ Significant from group II.

@ Significant from group III \& Significant from group IV.

Fig. (39): A Histogram: Illustrating mean values of IL- $1 \mathrm{~b}$ in rat myocardium specimens obtained from different groups of the examined animals. 


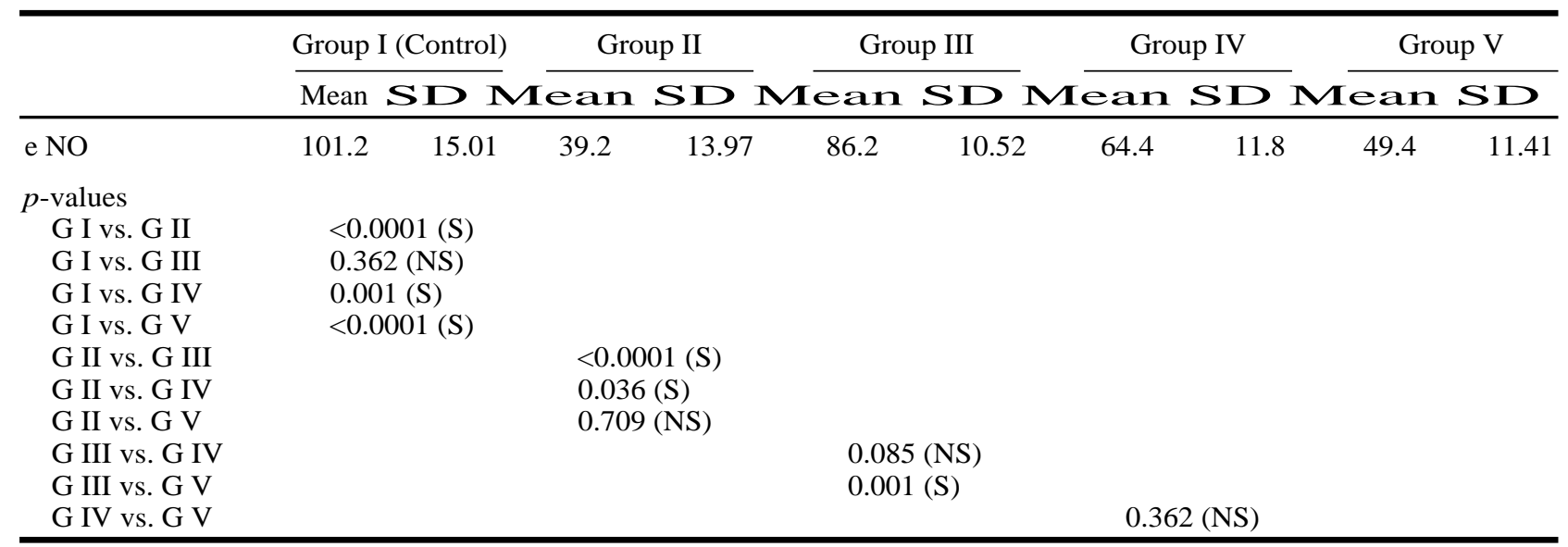

Fig. (40): A Table: Illustrating mean values of e NO in rat myocardium specimens obtained from different groups of the examined animals.

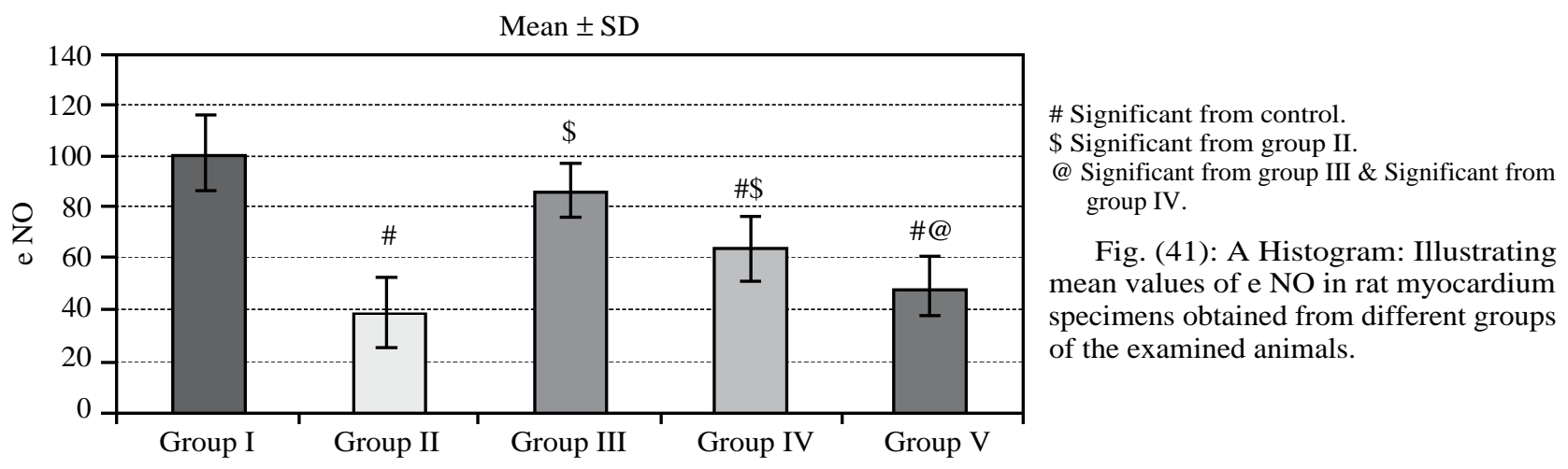

\section{Discussion}

In the current study, Light microscopic examination of rat heart specimens stained with haematoxylin and eosin stain, in rats treated with doxorubicin, showed: Completely degenerated myocardial fibers, markedly disturbed myocardial architecture with vacuolated sarcoplasm, markedly increased number of fibroblasts and ghost nuclei, marked increase in collagen tissue deposition between myocardial fibers and around a blood vessels with extensively fibrosis of rat myocardium. Electron microscopic examination of rat heart specimens of the same groups revealed markedly disturbed myocardial architecture with extensive sarcoplasmic rarefaction Most of mitochondria appear ballooned with lost cristae with disrupted myofibrils. This was in agreement with $[\mathbf{1 1}, \mathbf{1 2}, \mathbf{1 3}]$ who stated that in malignant cells, the primary cytotoxic effect of doxorubicin is exerted through the inhibition of topoisomerase II and DNA intercalation leading to reactive oxygen species production, DNA cross-linking and apoptosis. They added that the basic mechanism underlying doxorubicin cardiotoxicity is that doxorubicin interacts with iron metabolism and with resultant formation of an anthracycline-iron complex that induces lipid peroxidation, Moreover, DNA damage by reactive oxygen species production results in contractile impairment, irreversible myocardial damage and fibrosis with intracellular $\mathrm{Ca} 2+$ dysregulation.

In the present study, doxorubicin administration resulted in a significant increase in MDA levels in, whereas a significant decrease was observed in glutathion peroxidise levels compared to the control group. This was in agreement with [14-18] who stated that one of the most important indicators of the oxidative damage is the end product of lipid peroxidation, MDA. In oxidative tissue damage, increased levels of MDA is observed whereas a decrease is observed in the amount of endogenous antioxidant enzyme, glutathion peroxidise.

In the current study, doxorubicin administration resulted in a significant increase in the levels of proinflammatory cytokines such as IL- $1 \beta$ and TNF$\alpha$. This was in accordance with [10] who reported that IL- $1 \beta$ and TNF- $\alpha$ emerge in the early stage of inflammation leading to systemic tissue damage, oxidative explosion in the neutrophils and release of reactive oxygen species, via their common signalling molecules and that IL- $1 \beta$ plays an important role in inflammatory cascade by causing apoptosis and leukocyte infiltration. 
In the present study, Cardiac Troponin I (TPI) $\mathrm{CK}$, and CK-MB have been significantly increased following doxorubicin administration. This was in agreement with [19-21] who reported that TPI is one of the highly sensitive and specific parameters of myocardial damage and that doxorubicin has the potential to disrupt the cell membranes, which enables the release of intracellular proteins such as cardiac TPI, CK, and CK-MB.

In the current work, administration of spironolactone markedly ameliorated all histological and biochemical alterations especially when injected prior to doxorubicin administration. This was in agreement with [22] who stated that spironolactone could decrease overproduction of reactive oxygen species and can improve endothelial dysfunction in heart failure.

In the present work, spironolactone administration resulted in decreased levels of TNF alpha, IL$1 \mathrm{~b}$ especially if received before doxorubicin administration. This was in accordance with $[\mathbf{2 , 2 3 , 2 4}$, $\mathbf{2 5 , 2 6 ]}$ who reported that spironolactone can decrease proinflammatory cytokine especially if given before doxorubicin. They added that TNF- $\alpha$ is a cytokine that plays a dominant role in the inflammatory response and is synthesized by many cells, most commonly macrophages. The apoptotic and proliferative effects of tumour necrotic- $\alpha$ ( TNF$\alpha$ ) are thought to be mediated through two distinct receptors; apoptosis is induced when TNF receptor 1 (TNFR1) is stimulated.

\section{References}

1- TOWNSEND N., WILSON L., BHATNAGAR P., WICKRAMASINGHE K., RAYNER M. and NICHOLS M.: Cardiovascular disease in Europe: epidemiological update. Eur. Heart J., 37: 3232-45, 2016.

2- LIU G., LIU Y., WANG R., HOU T., CHEN C., ZHENG S. and DONG Z.: Spironolactone Attenuates Doxorubicininduced Cardiotoxicity in Rats. Cardiovascular Therapeutics, 34: 216-224, 2016.

3- AKPEK M., OZDOGRU I. and SAHIN O.: Protective effects of spironolactone against anthracyclineinduced cardiomyopathy. Eur. J. Heart Fail., 17: 81-89, 2015.

4- WEI J., NI J., HUANG D., CHEN M., YAN S. and PENG Y.: The effect of aldosterone antagonists for ventricular arrhythmia: A meta-analysis. Clin Cardiol., 33: 572-577, 2010.

5- CALVI E.N.V., NAHAS F.X., BARBOSA M.V., CALIL J.A., IHARA S.S.M., SILVA M.S., De FRANCO M.F. and FERREIRA L.M.: An experimental model for the study of collagen fibers in skeletal muscle. Acta Cirúrgica Brasileira, 27 (10): 681-686, 2012.

6- ESTEVA S., PANISELLO P., CASAS M., TORRELLA J.R., PAGÉS T. and VISCOR G.: Morphofunctional responses to anaemia in rat skeletal muscle. Journal of Anatomy, 212: 836-844, 2008.

7- LIVAK K.J. and SCHMITTGEN T.D.: Analysis of relative gene expression data using real-time quantitative PCR and the 2(- $\Delta \Delta \mathrm{C}(\mathrm{T}))$ method. Methods, 25: 402-408, 2001.

8- YANG L., LIU G., ZHU X., LUO Y., SHANG Y. and GU X.L.: The anti-inflammatory and antioxidant effects of leonurine hydrochloride after lipopolysaccharide challenge in broiler chicks. Poultry Science, 98: 1648-1657, 2019.

9- JEDDI S., GHEIBI S., KASHFI K., CARLSTRÖM M. and GHASEMI A.: Dose-Dependent Effects of LongTerm Administration of Hydrogen Sulfide on Myocardial Ischemia-Reperfusion Injury in Male Wistar Rats: Modulation of RKIP, NF- $\kappa \mathrm{B}$, and Oxidative Stress. Int. J. Mol. Sci., 21: 1415, 2020.

10- TOPAL I., BILGIN A. O., ÇIMEN F.K.. KURT N., SÜLEYMAN Z., BILGIN Y., ÖZÇIÇEK A. and ALTUNER A.: The effect of rutin on cisplatin-induced oxidative cardiac damage in rats. Anatol. J. Cardiol., 20: 136-42, 2018.

11- OCTAVIA Y., TOCCHETTI C.G., GABRIELSON K.L., JANSSENS S., CRIJNS H.J. and MOENS A.L.: Doxorubicin-induced cardiomyopathy: From molecular mechanisms to therapeutic strategies. J. Mol. Cell Cardiol., 52: 1213-25, 2012.

12- SHEVCHUK O.O., POSOKHOVA E.A., SAKHNO L.A. and NIKOLAEV V.G.: Theoretical ground for adsorptive therapy of anthracyclines cardiotoxicity. Exp. Oncol., 34: 314-22, 2012.

13- LODI M., PRIKSZ D., FULOP G.A., BODI B., GYONGYOSI A., NAGY L., KOVACS A., KERTÉSZ A.B., KOCSIS J., EDES I., CSANDI Z., CZURIGA I., KISVARDAY Z., JUHASZ B., LEKLI I., BAI P., TOTH A., PAPP Z. and CZURIGA D.: Advantages of prophylactic versus conventionally scheduled heart failure therapy in an experimental model of doxorubicin_induced cardiomyopathy. Journal of Translational Medicine, 19: 229, 2019.

14- NAZ1ROGLU M., KARAOGLU A. and AKSOY A.O.: Selenium and high dose vitamin $\mathrm{E}$ administration protects cisplatin-induced oxidative damage to renal, liver and lens tissues in rats. Toxicology, 195: 221-230, 2004.

15- SAHNA E., DENIZ E. and AKSULU H.E.: Myocardial ischemia-reperfusion injury and melatonin. Anadolu Kardiyol. Derg., 6: 163-168, 2006.

16- HIDEG K. and KÁLAI T.: Novel antioxidants in anthracycline cardiotoxicity. Cardiovasc. Toxicol., 7: 160-164, 2007.

17- KISAOGLU A., BOREKCI B., YAPCA O.E., BILEN H. and SULEYMAN H.: Tissue damage and oxidant / antioxidant balance. Eurasian J. Med., 45: 47-9, 2013.

18- TOUSSON E., HAFEZ E., ZAKI S. and GAD A.: The cardioprotective effects of L-carnitine on rat cardiac injury, apoptosis, and oxidative stress caused by amethopterin. Environ. Sci. Pollut. Res. Int., 23: 20600-20608, 2016.

19- BERTINCHANT J.P., POLGE A., JUAN J.M., OLIVALAURAIRE M.C., GIULIANI I. and MARTY-DOUBLE C.: Evaluation of cardiac troponin I and T levels as markers of myocardial damage in doxorubicin-induced cardio $\neg$ myopathy rats, and their relationship with echocar- 
diographic and histological findings. Clin. Chim. Acta., 329: 39-51, 2003).

20- KISMET E., VARAN A., AYABAKAN C., ALEHAN D., PORTAKAL O. and BÜYÜK-PAMUKÇU M.: Serum troponin $\mathrm{T}$ levels and echocardiographic evaluation in children treated with doxorubicin. Pediatr. Blood Cancer, 42: 220-224, 2004.

21- SIMOES R., SILVA L.M., CRUZ A.L., FRAGA V.G., SABINO A.P. and GOMES K.B.: Troponin as a cardiotoxicity marker in breast cancer patients receiving anthracycline-based chemotherapy: A narrative review. Biomedicine \& Pharmacotherapy, 107: 989-996, 2018.

22- WANG C.C., LEE A., LIU S. and CHANG C.T.: Spironolactone ameliorates endothelial dysfunction through the inhibition of the AGE/RAGEaxis in a chronic renal failure rat model. BMC Nephrology, 20: 351, 2019.

23- KISHORE R., TKEBUCHAVA T., SASI S.P., SILVER M., GILBERT H.Y., YOON Y.S., PARK H.Y., THORNE T., LOSORDO D.W. and GOUKASSIAN D.A.: Tumor necrosis factor-alpha signaling via TNFR $1 / \mathrm{p} 55$ is deleterious whereas TNFR2/p75 signaling is protective in adult infarct myocardium. Adv. Exp. Med. Biol., 691: 433-448, 2011.

24- WARPE V.S., MALI V.R., ARULMOZHI S., BODHANKAR S.L. and MAHADIK K.R.: Cardioprotective effect of ellagic acid on doxorubicin induced cardiotoxicity in wistar rats. Journal of Acute Medicine, 5: 1-8, 2015.

25- ZHANG J., CUI L., HAN X., ZHANG Y., ZHANG X., CHU X., ZHANG F., ZHANG Y. and CHU L.: Protective effect of tannic acid on acute doxorubicin-induced cardiotoxicity: Involvement of suppression of oxidative stress, inflammation and apoptosis. Biomed Pharmacotherapy, 93: 1253-1260, 2017.

26- OZKURT M., UZUNER K., ERKASAP N., KUS G., OZYURT R., UYSAL O., AKYAZI I. and KUTLAY O.: Erythropoietin Protects the Kidney by Regulating the Effect of TNF- $\alpha$ in L-NAME Induced Hypertensive Rats. Kidney Blood Press. Res., 43: 807-819, 2018.

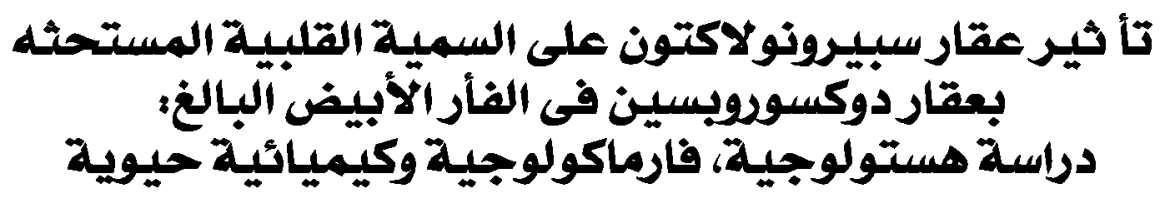

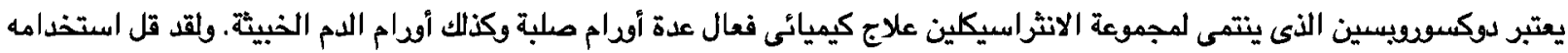
بسبب تأثيره السئ على عضلة القلب مثل الضمور المستمر، تغييرات فى رسم القلب وفثل القلب المحتقن. ولقد أثتبت الدراسات تأثير عقار سبيرونولاكتون فى تصسن تليف القلب الناتج عن استخدام هذا العقار. فهو يستخدم بالفعل لعلاج سمية القلب الناتجة عن استخدام دوكسوروبسين. هدف هذه الدراسة: هو توضيح الدو الوقائى والعلاجى السبيرونولاكتف في سمية القلب الناتجة عن استخدام ودوكسوبسين.

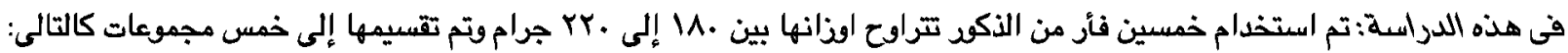

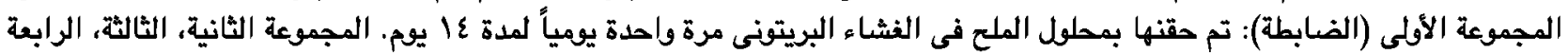

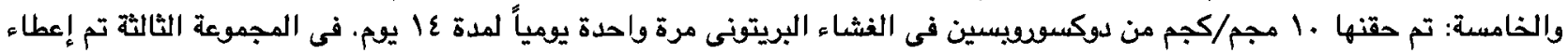

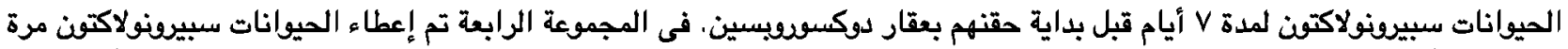

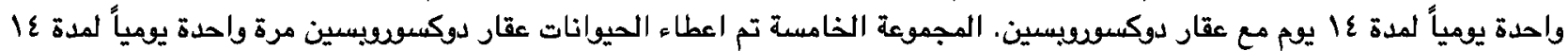

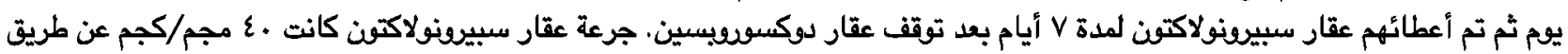

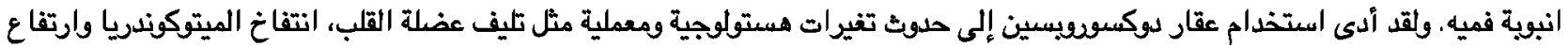

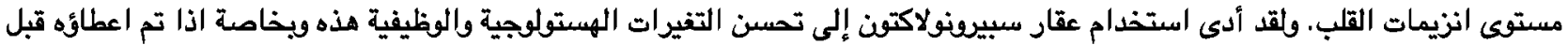
حقن عقار دوكسوبويسين. الخلاصة: هى قدرة عقار سبيرنولاكتون لمنع التغيرات الهستولوجية والوظيفية السلبية الناتجة عن استخدام عقار دوكسوربسين. 